\title{
The association between COMT rs4680 and 5-HTTLPR genotypes and concussion history in South African rugby union players
}

SARAH MC FIE ${ }^{1}$, SHAMEEMAH ABRAHAMS ${ }^{1}$, JON PATRICIOS ${ }^{2,3,4}$, JASON SUTER $^{5}$, MICHAEL POSTHUMUS $^{1} \&$ ALISON V SEPTEMBER $^{1}$

${ }^{1}$ University of Cape Town, South Africa; ${ }^{2}$ Morningside Sports Medicine Clinic, South Africa; ${ }^{3}$ University of Pretoria, South Africa; ${ }^{4}$ University of the Witwatersrand, South Africa and ${ }^{5}$ Sports Science Sports and Exercise Medicine Clinic, South Africa.

Correspondence: Alison V September, Division of Exercise Science and Sports Medicine, Department of Human Biology, University of Cape Town, Cape Town, South Africa. E-mail: alison.september@uct.ac.za

\section{Authors Contact details:}

\section{Sarah Mc Fie}

Address: 1 Boundary Road, Newlands, Cape Town, South Africa, 7700.

Email: sarah.mcfie@gmail.com

Affiliation: Division of Exercise Science and Sports Medicine, Faculty of Health Science, University of Cape Town, South Africa (PhD student).

\section{Shameemah Abrahams}

Address: 1 Boundary Road, Newlands, Cape Town, South Africa, 7700.

Email: padawankie@gmail.com

Affiliation: Division of Exercise Science and Sports Medicine, Faculty of Health Science, University of Cape Town, South Africa.

\section{Jon Patricios}

Address: Corner of Hill \& Rivonia Road, Sandton, 2196, South Africa Email: jpat@mweb.co.za 
Affiliations: Morningside Sports Medicine Clinic, South Africa; Section of Sports Medicine, University of Pretoria, South Africa; Department of Emergency Medicine, University of the Witwatersrand, South Africa.

\section{Jason Suter}

Address: 1 Boundary Road, Newlands, Cape Town, South Africa, 7700.

Email: Jason.Suter@eoh.com

Affiliation: Sports Science Sports and Exercise Medicine Clinic, Cape Town, South Africa.

\section{Michael Posthumus}

Address: 1 Boundary Road, Newlands, Cape Town, South Africa, 7700.

Email:mposthumus@me.com

Affiliations: Division of Exercise Science and Sports Medicine, Faculty of Health Science, University of Cape Town, South Africa.

\section{Corresponding Author: Alison V September}

Address: 1 Boundary Road, Newlands, Cape Town, South Africa, 7700.

Email: Alison.September@uct.ac.za

Affiliation: Division of Exercise Science and Sports Medicine, Faculty of Health Science, University of Cape Town, South Africa.

Facility where research took place: Division of Exercise Science and Sports Medicine, Faculty of Health Science, University of Cape Town, South Africa.

\section{Acknowledgements}

This study was funded by the South African National Research Foundation (A.V.S., grant number 90942), (M.P., grant numbers 93416:2015, 85534:2015). The South African National Research Foundation and the University of Cape Town funded S.A. and S.M. 


\section{Abstract}

The objective was to investigate the relationship between Catechol $O$ methyltransferase (COMT) rs4680 and serotonin-transporter-linked polymorphic region (5-HTTLPR) genotypes with concussion history and personality traits. Rugby players ("all levels": n=303), from high schools ("junior", $n=137$ ) and senior amateur and professional teams ("senior", $\mathrm{n}=166$ ), completed a concussion history questionnaire, Cloninger's Tridimensional Personality Questionnaire, and donated a DNA sample. Based on self-reported concussion history, participants were allocated into control (non-concussed, $n=140$ ), case (all) (previous suspected or diagnosed concussions, $\mathrm{n}=163$ ), or case (diagnosed only) (previous diagnosed concussion, $n=140$ ) groups. The COMT rs4680 Val/Val genotype was overrepresented in controls in all levels $(P=0.013$, OR:2.00, 95\% Cl:1.15-3.57; control:31\%, case all:17\%) and in juniors ( $P=0.003$, OR:3.57, 95\% Cl:1.459.09; control:37\%, case all:14\%). The junior Val/Val participants displayed increased "anticipatory worry" $(P=0.023)$. The 5-HTTLPR low expressing group was under-represented in controls when all levels were considered $(P=0.032 ;$ OR:2.02, 95\% Cl:1.05-3.90; control:13\%, case all:26\%) and in juniors ( $P=0.021$; OR:3.36, 95\% Cl:1.16-9.72; control:11\%, case all:25\%). The junior 5-HTTLPR low and intermediate expressing groups displayed decreased "harm avoidance" ( $P=0.009)$, "anticipatory worry" $(P=0.041)$, and "fear of uncertainty" $(P<0.001)$. This study provides preliminary indication that personality associated genetic variants can influence concussion in rugby.

Key words: concussion, rugby, personality, COMT, SLC6A4 


\section{Introduction}

Concussion is defined as "a complex pathophysiological process affecting the brain induced by traumatic biomechanical forces" (McCrory et al., 2013). Rugby union, hereafter referred to as rugby, is a sport characterised by frequent high impact collisions and is associated with a relatively high concussion risk compared to other team sports (Koh, Cassidy, \& Watkinson, 2003). In South African youth rugby, concussions occurred at an incidence of $6.8 / 1000$ player-match-hours, approximately one concussion every five matches, and made up one third of all time-loss injuries (Mc Fie et al., 2016). Furthermore, a study reported that over $60 \%$ of New Zealand high school rugby players have a history of concussion (Sye, Sullivan, \& McCrory, 2006), while $45 \%$ of adult Irish professional rugby players reported a concussion during a single monitored season (Fraas, Coughlan, Hart, \& McCarthy, 2014).

The long-term effects of numerous concussion injuries are currently unknown (Raftery, 2014). However, a history of multiple concussions was associated with increased risk of permanent neurological dysfunctions (Baugh et al., 2012; Mckee et al., 2009), common mental disorders (Gouttebarge, Aoki, Lambert, Stewart, \& Kerkhoffs, 2017), and mental health disturbances, including increased aggression and impulsivity (Kerr et al., 2014), in retired athletes. The relative frequency and the potential long-term effects of concussion, underline the need to identify factors that may modulate the risk of concussion in rugby. 
Recently, there has been exploration into the role of genetic variation in concussion susceptibility (Panenka et al., 2017). A systematic review described three potential mechanisms by which genetic polymorphisms may influence concussion risk (Panenka et al., 2017). Firstly, genetic modulation of the underlying neurophysiology or neuroanatomy could influence an individual's resilience to neurotrauma. Secondly, genetic polymorphisms that influence the susceptibility to comorbid conditions, for example attention deficit with hyperactivity disorder, may potentially modulate concussion risk. Thirdly, genetic variation may influence an individual's personality or behavioural profile, which may increase the risk of concussion.

It has been proposed that an athlete's personality might affect their concussion susceptibility. Specifically, increased concussion risk was observed in rugby players with high impulsivity scores (Hollis et al., 2009), collegiate athletes with elevated attention impulsivity, motor impulsivity, and total risk-taking impulsivity (Beidler, 2016), and ice-hockey players who claimed to play in order get rid of excess aggression (Gerberich et al., 1987). Personality may influence how a rugby player approaches or engages in contact situations, and thereby modify their concussion susceptibility.

An individual's personality is the result of a complex interplay between genetic and environmental factors (Bouchard, 1994). Personality is in part determined by the subtle differences in neural connections, neural architecture, and neurotransmission within certain key areas of the brain, including the prefrontal cortex (Davidson, 2001; Kennis, Rademaker, \& 
Geuze, 2013). Polymorphisms involved in the regulation of neurotransmitter systems are the most frequently investigated candidates in genetic association studies of personality, due to their potential roles in modulating neurotransmission (Balestri, Calati, Serretti, \& De Ronchi, 2014). Within those studies, two of the most routinely examined functional polymorphisms are the catechol-O-methyltransferase (COMT) rs4680 single nucleotide polymorphism (SNP) and the serotonin-transporter-linked polymorphic region (5-HTTLPR) (Balestri et al., 2014).

COMT is an enzyme responsible for the degradation of several catecholamines, including dopamine, epinephrine, and norepinephrine, from the synaptic cleft in the prefrontal cortex. A functional G>A substitution SNP, rs4680 or Val158Met, in the COMT gene causes an amino acid change from Valine (Val) to Methionine (Met) at codon 158. The Val allele has a three to four fold greater enzyme activity compared to the Met allele, and therefore, presumably has greater clearance of dopamine from the synaptic cleft (J. Chen et al., 2004).

This rs4680 polymorphism has a significant effect on dopaminergic neurotransmission in the prefrontal cortex (Meyer-Lindenberg et al., 2006) and has been associated with a variety of cognitive, psychiatric, behavioural, and personality measures (Montag, Jurkiewicz, \& Reuter, 2012; Stein, Fallin, Schork, \& Gelernter, 2005). Elevated dopamine signaling has been proposed to increase impulsive (Dalley \& Roiser, 2012; Pine, Shiner, Seymour, \& Dolan, 2010), risk-taking (Riba, Krämer, Heldmann, Richter, \& Münte, 2008), and 
novelty seeking (NS) (C R Cloninger, 1986) traits. In support, the COMT rs4680 Met allele, characterised by decreased dopamine degradation, was associated with increased impulsivity (Soeiro-De-Souza, Stanford, Bio, Machado-Vieira, \& Moreno, 2013), risk-taking (Amstadter et al., 2012), and NS scores (Montag et al., 2012). Considering COMT rs4680's involvement in impulsive and risk-taking personality traits, it is reasonable to propose that the COMT rs4680 SNP may influence concussion susceptibility in sport.

The 5-HTTLPR polymorphism, within the serotonin transporter gene (SLC6A4), is a 43 base pair insertion or deletion, resulting in a short allele (S), with 14 repeat units, or a long allele $(L)$ comprising 16 repeat units (Heils et al., 1996). The $S$ allele results in reduced serotonin transporter expression and function (Heils et al., 1996; Lesch et al., 1996). Furthermore, within the 5HTTLPR is an A>G SNP (SLC6A4 rs25531) that modulates the functional effect of the 5-HTTLPR by interfering with a putative transcription factor binding site, such that the $L_{G}$ allele has significantly lower expression than the $\mathrm{L}_{\mathrm{A}}$ allele (Hu et al., 2006).

Serotonin signaling plays a significant role in personality and behaviour (Carver \& Miller, 2006; Nordquist \& Oreland, 2010) and the 5-HTTLPR and SLC6A4 rs25531 variants have previously been associated with several personality measures (Balestri et al., 2014; Lee \& Prescott, 2014). Increased serotonergic transmission is linked to heightened harm avoidance (HA) (C Robert Cloninger, 1987), while decreased serotonin production, achieved via tryptophan depletion, resulted in increased impulsivity measures in a number 
of studies (Dalley \& Roiser, 2012). The 5-HTTLPR S allele, presumably with higher serotonin signaling, has been associated with increased HA (Lesch et al., 1996), impulsivity (Sonuga-Barke et al., 2011; Walderhaug, Herman, Magnusson, Morgan, \& Landro, 2010), and risk-taking measures (Stoltenberg, Lehmann, Anderson, Nag, \& Anagnopoulos, 2011). Hence, it was of interest to investigate whether the 5-HTTLPR and SLC6A4 rs25531 variants might also influence concussion susceptibility in sport.

To the best of the authors' knowledge there have been no published investigations into the role of personality-associated genetic markers and concussion susceptibility in sport. Therefore, the aim of the study was to investigate the relationship between COMT rs4680 and 5-HTTLPR genotypes, concussion history, and personality traits in a rugby-playing population.

\section{Methods}

\section{Participant recruitment}

The investigation followed a case-control genetic association study design and the study is presented in accordance with the "Strengthening the Reporting of Genetic Association Studies" (STREGA) statement for reporting the results of genetic association studies (Little et al., 2009). Ethical approval for the study was obtained from the Human Research Ethics Committee of the University of Cape Town. The Western Cape Education Department, and 
relevant school and club administrators, granted permission to conduct research at the respective high schools and clubs. All participants gave written informed consent and, in the case of minors, informed assent from the minor and informed consent from a parent or legal guardian was obtained. Participants were assigned to control or case groups after recruitment, based on their self-reported concussion history.

A total of 693 apparently healthy male rugby players, from high schools, senior amateur-level clubs, and professional teams, were invited to participate in the study between January 2013 and August 2015. Four hundred and eighty-seven rugby players agreed to participate and completed the consent and/or assent forms. Participants were then required to (i) complete the study questionnaire containing; personal details, medical, and sporting history questionnaire, a concussion history questionnaire, and the Tridimensional Personality Questionnaire (TPQ) (C Robert Cloninger, 1987), and (ii) donate a non-invasive, self-administered buccal swab for DNA collection. The adult participants completed the consent form and study questionnaire in a single session. For the junior (under-18) participants, consent was first required from both parent and junior before the study questionnaire was completed at a subsequent time point. Junior participants who had completed consent and assent forms, but did not submit the study questionnaire were excluded $(n=67)$. 


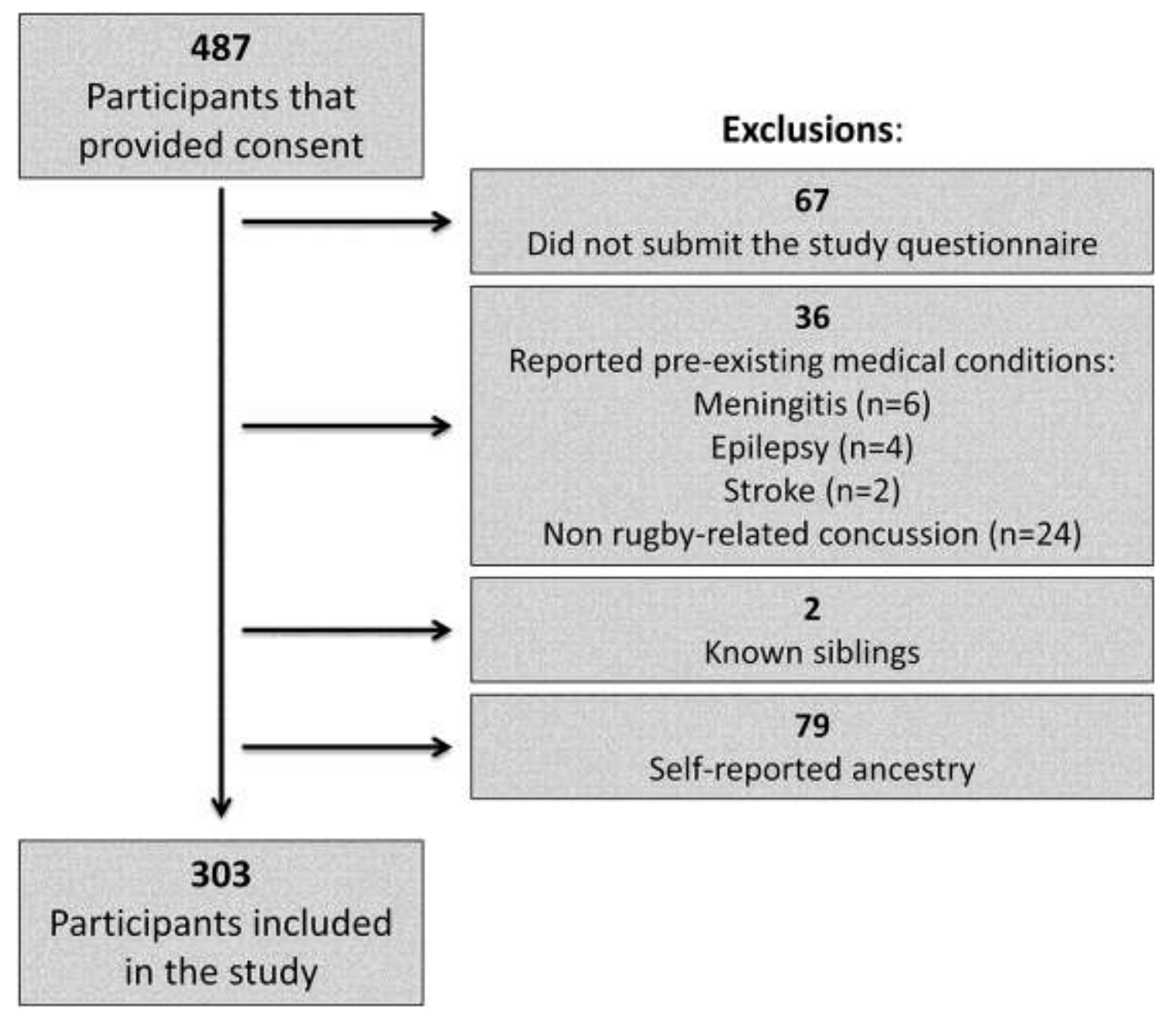

Figure 1: A diagramatic description of the participant exclusion criteria applied in the study.

The participant exclusions are summarised in Figure 1. Participants were excluded if they had previously been diagnosed with meningitis $(n=6)$, epilepsy $(n=4)$, stroke $(n=2)$, or had sustained a non rugby-related concussion $(n=24)$. Known siblings of enrolled participants were excluded $(n=2)$. Participants were grouped according to self-reported ancestry due to potential population stratification effects, which may significantly confound the results of genetic association studies (Thomas \& Witte, 2001). Because of sample size and statistical power, only participants of self-reported white ancestry were included and participants of other ethnicities were excluded $(n=79)$. 
A total of 303 participants were included in the study (aged $12-39$ years old). Due to the proposed effect of age on personality traits (Fresán, Robles-García, López-Avila, \& Cloninger, 2011) and the difference in rugby exposure between levels of play, analysis was completed on "all levels" (all participants combined: $n=303$, age: $19.7 \pm 4.2$ years), and additionally in a "junior" (high school players: $n=137$, age: $16.3 \pm 1.3$ years) and a "senior" (114 senior amateur club and 52 senior professional players: $n=166$, age: $22.4 \pm 3.7$ years) cohort.

\section{Concussion history}

Concussion was defined according to the Zurich Consensus statement (McCrory et al., 2013). Briefly, for this study, concussion was defined as a direct, or indirect blow, to the head during a rugby-related activity, that resulted in a set of clinical signs and symptoms that may or may not have involved loss of consciousness. The self-reported concussion history questionnaire required participants to provide details of their four most recent concussions. Specifically, information was collected on the date and mechanism of concussion injury, whether the concussion was diagnosed by a medical professional, the occupation of that medical professional (medical doctor, physiotherapist, nurse, paramedic), the symptoms experienced, and the duration of symptoms. Participants selected the relevant symptoms from a concussion symptom checklist, which was constructed from the Sports Concussion Assessment Tool (3 ${ }^{\text {rd }}$ edition) (Guskiewicz et al., 2013). 
Concussions that were reported to have been diagnosed by a medical professional (doctor, physiotherapist, nurse, paramedic), and qualified with one or more concussion symptoms, were termed "diagnosed concussions". Concussions that were not diagnosed by medical professional, but were described in conjunction with concussion symptoms, were defined as "suspected concussions".

In this study, the control group included all individuals reporting no suspected or diagnosed concussions, while the "case (all)" group included all participants with a minimum of one suspected or diagnosed concussion. The case subgroup, "case (diagnosed only)", only included participants with one or more diagnosed concussions, thus excluding suspected concussions. Of the 303 participants that met the inclusion criteria, 140 participants were assigned to the control group (junior: $n=74$; senior: $n=66$ ) and 163 participants assigned to the case (all) group (junior: $n=63$; senior: $n=100$ ). Of the 163 case (all) participants, 140 were additionally allocated into the case (diagnosed only) subgroup (junior: $n=53$; senior: $n=87$ ).

\section{Medical and sporting history}

Participants were asked to disclose any current or previously diagnosed medical conditions and describe details of their lifetime rugby and sporting participation, including the total years of participation, highest level of play, and playing position. 
Cloninger's TPQ assesses three dimensions of personality, namely NS, HA, and reward dependence (RD), each with four subscales (Table I) (C Robert Cloninger, 1987). NS is defined as "a heritable tendency toward frequent exploratory activity and intense excitement in response to novel stimuli" and is indicative of risk-taking and impulsive behavior. HA is the "heritable tendency to avoid aversive situations" and is described as a measure of the perceived risk and anxiety of a given situation. RD is "a tendency to respond intensely to signals of reward" (C Robert Cloninger, 1987).

Participants without a self-reported English language comprehension did not complete the TPQ $(n=18)$. Within the TPQ, there were two validation items (blank questions with true and false answer boxes) to test for carelessness and inaccuracy of responses. If one, or both, of these validation items were answered the participant was removed from the TPQ analysis $(n=43)$. Of the 303 participants, $243(80 \%)$ completed the TPQ and were included in the analysis (junior: $n=93,69 \%$; senior $n=150,90 \%$ ).

\section{DNA extraction}

A buccal cheek swab was collected from participants using the Isohelix® SK2 (Cell projects Ltd, Kent, UK) or the Epicentre ${ }^{\circledR}$ Catch All ${ }^{\mathrm{TM}}$ (Epicentre ${ }^{\circledR}$ Biotechnologies, WI, USA) buccal swabs and DNA extracted as per the manufacturers' instructions. 


\section{Table I}

Personality characteristics for high and low scoring for the novelty seeking (NS), harm avoidance (HA), and reward dependence (RD) dimensions, and each of the four corresponding dimension subscales, as measured by the Tridimensional Personality Questionnaire (TPQ).

Table adapted from Cloninger et al. 1987.

\begin{tabular}{cclc}
\hline Dimension & Low & High & Items (n) \\
\hline NS & Deliberate and reserved & Risk taking and impulsive & 33 \\
NS1 & Stoic rigidity & Increased exploratory excitability & 8 \\
NS2 & Reflection & Impulsive & 8 \\
NS3 & Reserved & Extravagant & 7 \\
NS4 & Regimented & Disorderly & 10 \\
HA & Carefree and confident & Cautious and worried & 34 \\
HA1 & Uninhibited optimism & Increased anticipatory worry & 10 \\
HA2 & Confident & Increased fear of uncertainty & 7 \\
HA3 & Gregarious & Shy with strangers & 7 \\
HA4 & Vigourous & Increased fatigability and asthenia & 10 \\
RD & Detached and independent & Sentimental and social & 29 \\
RD1 & Insensitive & Sentimental & 5 \\
RD2 & Irresolute & Persistent & 8 \\
RD3 & Detached & Attached & 11 \\
RD4 & Independent & Dependent & 5 \\
\hline
\end{tabular}




\section{Genotyping}

DNA was genotyped, for the COMT rs4680, 5-HTTLPR, and SLC6A4 rs25531 genetic polymorphisms, using standard polymerase chain reaction (PCR) and restriction fragment length polymorphism analysis as previously described (van Breda, Collins, Stein, \& Rauch, 2015; Wendland, Martin, Kruse, Lesch, \& Murphy, 2006).

Negative controls (no DNA added) and two samples of known genotypes (positive controls) were included in each 96-well PCR plate to detect potential DNA contamination. Two independent investigators confirmed all genotypes. All laboratory work was completed at the Division of Exercise Science and Sports Medicine within the University of Cape Town.

\section{Statistics}

Power analysis was calculated using QUANTO version 1.2.4 (http://biostats.usc.edu/software) to determine adequate sample size. The minimum sample of control and case pairs calculated to be sufficient to detect an odds ratio of 2.0 , at $80 \%$ statistical power and $5 \%$ significance level, was between 71 and 74 for both COMT rs4680 (minor allele frequency of 0.4 to 0.5 ) and the 5-HTTLPR (minor allele frequency 0.4 to 0.5 ). Statistical analysis was performed using the language and environment $R$ statistical program ( $R$ Core Team, 2013), STATA ${ }^{\circledR}$ version 13 (Stata Corporation, College Station, TX, USA), and STATISTICA version 13 (StatSoft Inc., Tulsa, OK, USA). All 
figures were created using GraphPad Prism statistical software version 5.03 (GraphPad Software, San Diego, CA, USA).

The Shapiro Wilk test was used to investigate whether the data sets were normally distributed. All participant characteristic data and TPQ dimension scores were normally distributed. A One-way Analysis of Variance (ANOVA), with Tukey's post-hoc test, was used to observe differences in participant characteristics data between groups.

The genetics and SNPassoc packages in R (González et al., 2007; Warnes \& Leisch, 2006) were used to calculate the Hardy-Weinberg equilibrium (HWE) probabilities and genotype or allele frequency distributions. Using the SNPassoc package, a Pearson's Chi-squared test was used to compare differences in genotype and allele frequencies between control and case groups and calculate the resultant odds ratios (OR) with $95 \%$ confidence intervals $(95 \% \mathrm{Cl})$. Genotype and allele frequency analyses were adjusted for age as a possible confounding covariate. Based on the previously reported effect of the rs25531 SNP on serotonin transporter gene transcription levels (Hu et al., 2006), the $S_{A} / S_{A}(n=49 ; 18 \%)$ genotypes were classified as the low expressing group ("low": $n=49 ; 18 \%)$; the $S_{A} / L_{A}(n=129,47 \%), S_{A} / L_{G}(n=18$, 7\%), $L_{A} / L_{G}(n=21,8 \%)$, and $L_{G} / L_{G}(n=0,0 \%)$ were grouped as the intermediate expressing group ("intermediate": $n=168,62 \%)$; and $\mathrm{L}_{A} / \mathrm{L}_{A}(\mathrm{n}=56,21 \%)$ genotypes were termed the high expressing group ("high": n=56, 21\%). The combined 5-HTTLPR and SLC6A4 rs25531 genotype will hereafter be referred to as the 5-HTTLPR genotype. 
A Chi-squared test for trend was completed on the genotype frequencies across participants reporting zero, one, and two or more concussions, to investigate possible genotype effects on the number of reported concussions.

COMT rs4680 and 5-HTTLPR were analysed as an allele construct using the haplo.score package in R (Schaid, Rowland, Tines, Jacobson, \& Poland, 2002). The allele construct analysis combined the COMT and 5HTTLPR genotype data to infer frequencies for each potential COMT and 5HTTLPR allele construct (Met-S ${ }_{A}$, Met- $L_{A}$, Met- $L_{G}$, Val-S $S_{A}$, Val- $L_{A}$, and Val- $L_{G}$ ) in the control and case groups. A Pearson's Chi-squared test was then used to compare the frequencies of allele constructs between control and case groups

A one-way analysis of covariance (ANCOVA), with age as a covariate, was used to examine the relationship between TPQ scores and genotype groups. If significant differences $(P<0.05)$ were seen in dimension (NS, HA, and RD) scores, then analysis was completed on dimension subscales and the results included in tables. A review of the codominant COMT rs4680 Val>Met polymorphism found an overall association between COMT rs4680 and NS and HA traits when the Met allele carriers (Met/Met and Met/Val genotypes) were compared to the Val/Val individuals (Montag et al., 2012). Therefore in this study, a combined COMT rs4680 Met/Met and Met/Val genotype group was compared to the Val/Val genotype for the TPQ analysis. Due to the dominant effect of the 5-HTTLPR S allele (Hu et al., 2006) a 
combined low and intermediate 5-HTTLPR group was compared to the high genotype group.

The collective interactions between concussion history groups (control, case all, and case diagnosed only), specific genotypes (COMT rs4680 or 5HTTLPR), and personality traits (NS, HA, and RD) were further investigated using generalized structural equation modeling. Concussion history was coded in the model as the case (all), or case (diagnosed only), group compared to the control group. Separate models were computed for COMT rs4680 and 5-HTTLPR. The model analysis tested whether each genotype was associated with concussion history or TPQ dimension when compared to a designated reference genotype. The COMT rs4680 Val/Val genotype and the 5-HTTLPR low genotype group were selected as the reference genotypes for the COMT rs4680 and 5-HTTLPR models, respectively. $P$ values less than 0.05 were accepted as statistically significant.

\section{Results}

\section{Participant characteristics}

Combining all levels of play, the control group (age: $18.8 \pm 3.6$ years, $n=140$; weight: $87.7 \pm 16.1 \mathrm{~kg}, \mathrm{n}=136$ ) was younger and lighter than the case (all) group (age: $20.4 \pm 4.5$ years, $n=163, P=0.001$; weight: $91.8 \pm 16.8 \mathrm{~kg}, \mathrm{n}=158$, $P=0.035$, Table II). The junior control and case (all) groups were similar in age $(P=0.721)$, but the senior control group (age: $21.7 \pm 3.3$ years, $n=66$ ) was 


\section{Table II}

The general participant characteristics of junior (high school) and senior (senior amateur club and professional) rugby players without a previous suspected or diagnosed concussion (control), with a minimum of one suspected or diagnosed concussion (case all), and additionally case (all) participants with one or more diagnosed concussions (case diagnosed only).

\begin{tabular}{|c|c|c|c|c|c|}
\hline Level of play & Control & Case (all) & $P$ value $^{\text {a }}$ & Case (diagnosed only) & $P$ valu \\
\hline \multicolumn{6}{|l|}{ All Levels } \\
\hline $\mathrm{n}$ & 140 & 163 & & 140 & \\
\hline Age (years) & $18.8 \pm 3.6(140)$ & $20.4 \pm 4.5(163)$ & 0.001 & $20.2 \pm 4.2(140)$ & 0.00 \\
\hline Height (m) & $1.82 \pm 0.08(136)$ & $1.83 \pm 0.08(161)$ & 0.140 & $1.83 \pm 0.09(138)$ & 0.19 \\
\hline Weight (kg) & $87.7 \pm 16.1(136)$ & $91.8 \pm 16.8(158)$ & 0.035 & $91.8 \pm 17.5(135)$ & 0.04 \\
\hline BMI $\left(\mathrm{kg} / \mathrm{m}^{2}\right)$ & $26.6 \pm 3.6(133)$ & $27.2 \pm 3.7(155)$ & 0.151 & $27.3 \pm 3.8(132)$ & 0.14 \\
\hline Rugby exposure (years) & $10.9 \pm 4.1(140)$ & $11.2 \pm 4.5(162)$ & 0.586 & $11.0 \pm 4.7(139)$ & 0.86 \\
\hline \multicolumn{6}{|l|}{ Junior } \\
\hline $\mathrm{n}$ & 74 & 63 & & 53 & \\
\hline Age (years) & $16.3 \pm 1.3(74)$ & $16.4 \pm 1.4(63)$ & 0.721 & $16.2 \pm 1.4(53)$ & 0.87 \\
\hline Height (m) & $1.80 \pm 0.09(71)$ & $1.80 \pm 0.08(61)$ & 0.698 & $1.80 \pm 0.08(51)$ & 0.99 \\
\hline Weight (kg) & $79.9 \pm 15.5(71)$ & $81.7 \pm 16.5(59)$ & 0.545 & $80.7 \pm 17.3(49)$ & 0.80 \\
\hline BMI $\left(\mathrm{kg} / \mathrm{m}^{2}\right)$ & $25.0 \pm 3.5(68)$ & $25.1 \pm 4.0(56)$ & 0.806 & $25.0 \pm 4.1(46)$ & 0.95 \\
\hline Rugby exposure (years) & $8.8 \pm 2.7(74)$ & $8.8 \pm 3.1(63)$ & 0.875 & $8.5 \pm 3.3(53)$ & 0.60 \\
\hline \multicolumn{6}{|l|}{ Senior } \\
\hline $\mathrm{n}$ & 66 & 100 & & 87 & \\
\hline Age (years) & $21.7 \pm 3.3(66)$ & $22.9 \pm 3.8(100)$ & 0.038 & $22.6 \pm 3.5(87)$ & 0.09 \\
\hline Height (m) & $1.84 \pm 0.08(65)$ & $1.85 \pm 0.08(100)$ & 0.452 & $1.85 \pm 0.08(87)$ & 0.43 \\
\hline
\end{tabular}


Weight $(\mathrm{kg})$

BMI $\left(\mathrm{kg} / \mathrm{m}^{2}\right)$

Rugby Exposure (years)
$96.2 \pm 12.0(65)$

$28.3 \pm 2.9(65)$

$13.3 \pm 4.2(66)$

$\begin{array}{cc}97.8 \pm 13.9(99) & 0.436 \\ 28.4 \pm 2.9(99) & 0.835 \\ 12.6 \pm 4.7(99) & 0.377\end{array}$

0.377
$98.2 \pm 14.3(86)$

$28.5 \pm 3.0(86)$

$12.5 \pm 4.8(86)$
0.36

0.71

0.30

Data are expressed as mean \pm standard deviation with the number of participants with non-missing data $(\mathrm{n})$ in parentheses. Unadjusted $P$ values for ${ }^{a}$ control versus case (all) and ${ }^{b}$ control versus case (diagnosed only) are displayed. Statistical significant differences $(P<0.05)$ between control and case groups are displayed in bold. BMI: Body Mass Index. 
younger than the senior case (all) group (age: $22.9 \pm 3.8$ years, $n=100$, $P=0.038$, Table II). The control and case (all) groups within the junior and senior cohorts were similar in height (junior: $P=0.698$; senior: $P=0.452$ ), weight (junior: $P=0.545$; senior: $P=0.436$ ), body mass index (BMI) (junior: $P=0.806$; senior: $P=0.835$ ), and rugby exposure (junior: $P=0.875$; senior: $P=0.377$, Table II).

There were no significant COMT rs 4680 or 5 -HTTLPR genotype effects on age (COMT rs4680: $P=0.514 ; 5$-HTTLPR: $P=0.140$ ), height (COMT rs4680: $P=0.266$; 5-HTTLPR: $P=0.882$ ), weight (COMT rs4680: $P=0.988$; 5HTTLPR: $P=0.714$ ), BMI (COMT rs4680: $P=0.718$; 5-HTTLPR: $P=0.573$ ), or rugby exposure (COMT rs4680: $P=0.865 ; 5$-HTTLPR: $P=0.111$ ).

\section{COMT rs4680 genotype and allele frequency distributions}

All levels. When all participants were combined, the COMT rs4680 genotype distribution was significantly different between the control and the case (all) $(P=0.040)$ and case (diagnosed only) $(P=0.041)$ groups. Specifically, the Val/Val genotype was over-represented in the control group $(31 \%, n=41)$ compared to the case (all) group $(17 \%, n=27, \mathrm{Val} / \mathrm{Val}$ vs. Met/Met $+\mathrm{Met} / \mathrm{Val}$ : $P=0.013$, OR: $2.00,95 \% \mathrm{Cl}: 1.15-3.57$ ) and the case (diagnosed only) subgroup $(18 \%, \mathrm{n}=24, \mathrm{Val} / \mathrm{Val}$ vs. Met/Met $+\mathrm{Met} / \mathrm{Val}: P=0.022$, OR: 1.92 , 95\% Cl: 1.09 - 3.45; Figure 2a). Furthermore, there was a general linear trend for the $\mathrm{Val} / \mathrm{Val}$ genotype frequency to decrease across participants 
a) All levels

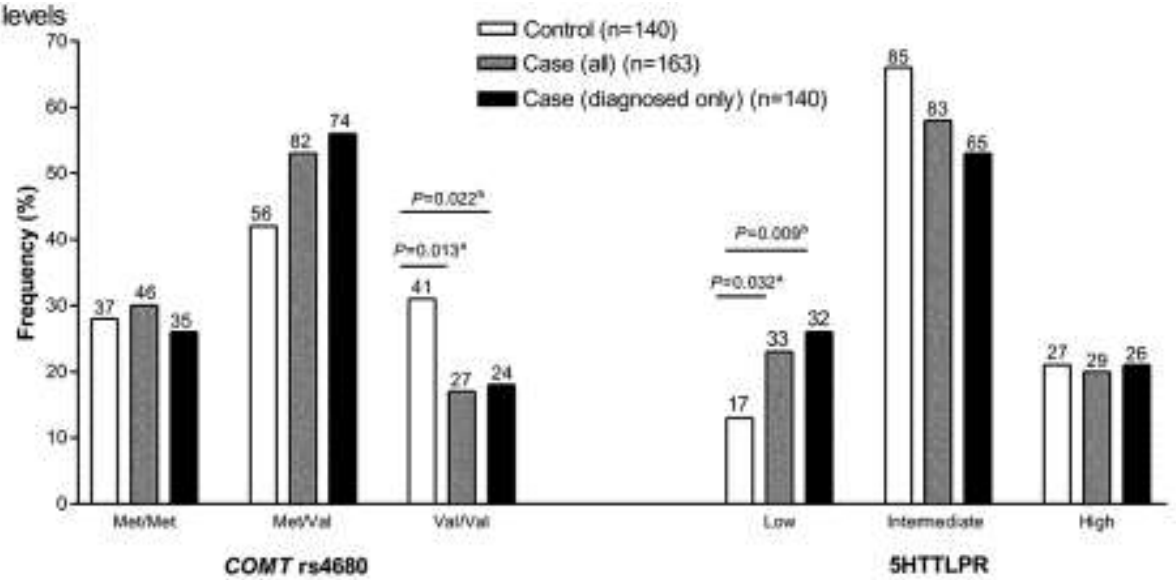

b) Junior

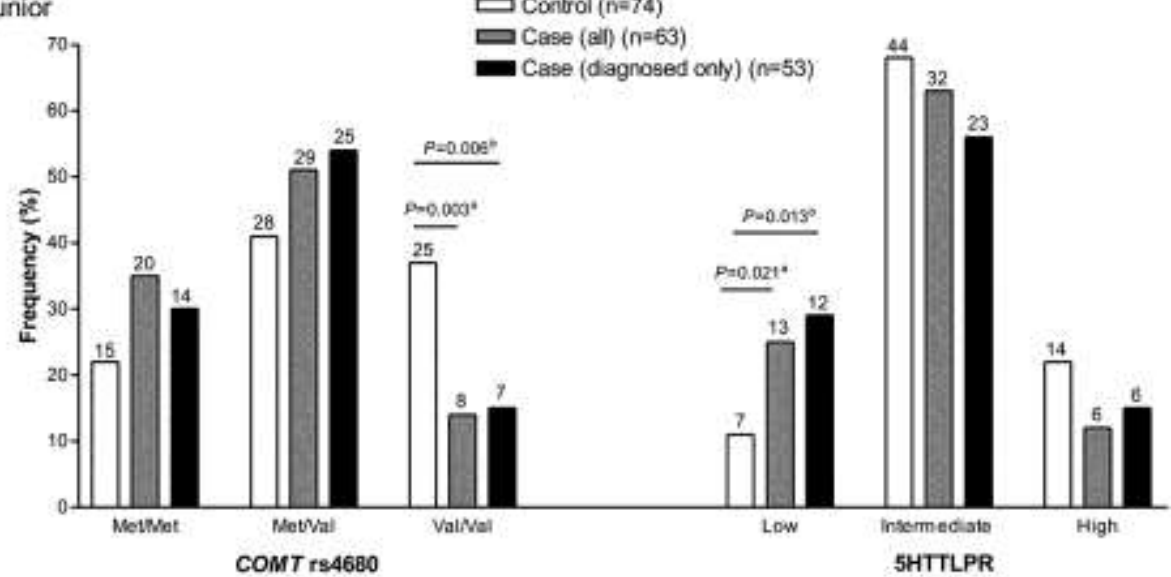

c) Senio

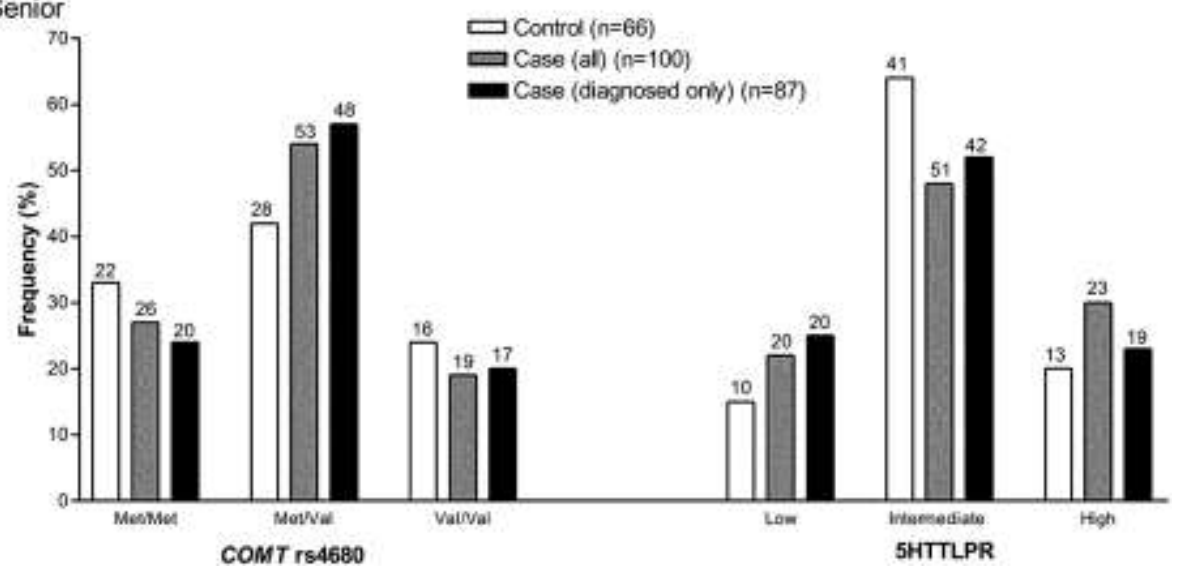

Figure 2: The COMT rs4680 and 5-HTTLPR, in conjunction with SLC6A4 rs25531 ("low": $\mathrm{S}_{\mathrm{A}} / \mathrm{S}_{\mathrm{A}}$; "intermediate": $S_{A} / L_{A}, S_{A} / L_{G}, L_{A} / L_{G}, L_{G} / L_{G}$; "high": $\left.L_{A} / L_{A}\right)$, genotype frequency distributions between rugby players without a previous suspected or diagnosed concussion (control), with a minimum of one suspected or diagnosed concussion (case all), and case (all) participants with one or more diagnosed concussions (case diagnosed only) when a) all participants (junior and senior) were combined, b) in the junior cohort (high school players), and c) in the senior cohort (senior amateur and professional players). Significant $(P<0.05)$ age-adjusted $P$ values and the number of non-missing participants in each group are displayed for ${ }^{a}$ control vs. case (all) group and ${ }^{b}$ control vs. case (diagnosed only) subgroup. 
reporting zero $(31 \%, n=41)$, one $(20 \%, n=14)$, or two or more concussions $(15 \%, \mathrm{n}=13, P=0.007)$.

Junior. When only the junior participants were analysed, the COMT rs4680 genotype distribution was significantly different between junior control and junior case (all) ( $P=0.012)$ and case (diagnosed only) $(P=0.024)$ groups, with the $\mathrm{Val} / \mathrm{Val}$ genotype similarly over-represented in the junior control group $(37 \%, n=25)$ compared to the junior case (all) group $(14 \%, n=8$, Val/Val vs. Met/Met + Met/Nal: $P=0.003$, OR: $3.57,95 \% \mathrm{Cl}: 1.45-9.09)$ and junior case (diagnosed only) subgroup $(15 \%, n=7$, Val/Val vs. Met/Met + Met/Val: $P=0.006$, OR: $3.45,95 \% \mathrm{Cl}: 1.35$ - 9.09; Figure 2b). Furthermore, the Val allele was over-represented in the junior control $(57 \%, n=78)$ group compared to the junior case (all) group $(39 \%, n=45, P=0.007)$ and junior case (diagnosed only) subgroup ( $42 \%, n=39, P=0.037)$. There was also a general linear trend for the $\mathrm{Val} / \mathrm{Val}$ genotype frequency to decrease across junior participants reporting zero $(37 \%, n=25)$, one $(15 \%, n=5)$ and two or more concussions $(13 \%, \mathrm{n}=3, P=0.007)$.

Senior. No significant differences in the COMT rs4680 genotype frequency distributions were noted between the senior control and the senior case groups (case all: $P=0.333$; case diagnosed only: $P=0.210$; Figure $2 c$ ). The COMT rs4680 polymorphism was in HWE for all control and case groups $(P>0.05)$. 


\section{5-HTTLPR genotype and allele frequency distributions}

All levels. The 5-HTTLPR genotype frequency distributions were not significantly different between the control and case (all) group ( $P=0.101)$, but there was a difference between the control and the case (diagnosed only) subgroup $(P=0.028)$. Further analysis revealed that the 5 -HTTLPR low group was under-represented in the control group $(13 \%, n=17)$ compared to both the case (all) group $(22 \%, \mathrm{n}=32$, low vs. intermediate + high: $P=0.032$, OR: $2.02,95 \% \mathrm{Cl}: 1.05-3.90)$ and case (diagnosed only) subgroup (25\%, $\mathrm{n}=31$, low vs. intermediate + high: $P=0.009$, OR: $2.39,95 \% \mathrm{Cl}: 1.22-4.65$; Figure 2a). There were no significant general linear trends in the 5-HTTLPR frequency distributions across those participants reporting zero, one, or two or more concussions $(P=0.075)$.

Junior. Similarly in the junior cohort, there were differences in the 5-HTTLPR genotype frequencies between the junior control and the junior case (all) $(P=0.046)$ and junior case (diagnosed only) $(P=0.042)$ groups. The 5 -HTTLPR low group was under-represented in the junior control $(11 \%, n=7)$ compared the junior case (all) $(26 \%, n=13$, low vs. intermediate + high: $P=0.021$, OR: $3.36,95 \% \mathrm{Cl}: 1.16-9.72)$ and junior case (diagnosed only) subgroup (29\%, $\mathrm{n}=12$, low vs. intermediate + high: $P=0.012$, OR: $3.86,95 \% \mathrm{Cl}: 1.30-11.52$ Figure 2b). However, there were no significant linear trends in the frequency 5-HTTLPR groups across those reporting zero, one, or two or more concussions $(P=0.103)$. 
Senior. There were no significant differences in the 5-HTTLPR genotype frequencies between senior control and senior case groups (case all: $P=0.564$; case diagnosed only: $P=0.313$; Figure $2 \mathrm{c}$ ). The 5 -HTTLPR polymorphism was in HWE for all control and case groups $(P>0.05)$.

\section{Allele construct distribution}

All levels. Inferred allele constructs were created from COMT rs4680 and 5HTTLPR genotype data. Of the possible constructs only four (Met-S ${ }_{A}$, Met- $L_{A}$, Val-S $S_{A}$, and $\mathrm{Val}-\mathrm{L}_{\mathrm{A}}$ ) were expressed at a frequency above $4 \%$ in all analyses. When all levels of play were combined, the Met-S $S_{A}$ allele construct was significantly under-represented in the control group (19\%) compared to the case (all) group (32\%, additive model: $P=0.001$, hap.score=3.19) and case (diagnosed only) subgroup (33\%, additive model: $P=0.003$, hap.score=2.95).

Junior. The Met-S ${ }_{A}$ allele construct was also significantly under-represented in the junior control group (19\%) compared to the case (all) group (34\%, additive model: $P=0.003$, hap.score $=3.26)$ and case (diagnosed only) subgroup (33\%, additive model: $P=0.005$, hap.score=2.84). Furthermore, the Val- $\mathrm{L}_{a}$ allele construct was over-represented in junior control $(31 \%, n=23)$ compared to the junior case (all) group (17\%, $\mathrm{n}=10$, additive model: $P=0.005$, hap.score=-2.78) and junior case (diagnosed only) subgroup $(16 \%, n=8$, additive model: $P=0.015$, hap.score $=-2.43)$. 
Senior. There were no differences in the frequency distribution of allele constructs in the senior cohort $(P>0.05)$.

\section{COMT rs4680, 5-HTTLPR, and TPQ}

All levels. There were no significant differences in the three TPQ dimension scores between COMT rs4680 (Met/Met + Met/Val vs. Val/Val, NS: $P=0.865$; HA: $P=0.354$; RD: $P=0.279$ ) and 5-HTTLPR (low + intermediate vs. high, NS: $P=0.727$; HA: $P=0.795$; RD: $P=0.250$; Table III) genotypes in all levels of play combined.

Junior. There were no significant differences in NS $(P=0.179)$, HA $(P=0.059)$ or RD ( $P=0.101$; Table III) between the junior Met/Met and Met/Val genotype group and the junior Val/Val genotype. Although, within the HA subscales, the junior Val/Val group (HA1: $4.7 \pm 2.4, n=20$ ) had statistically higher HA1 ("anticipatory worry") scores than the junior Met/Met and Met/Val group (HA1: $3.4 \pm 2.0, n=64$, Met/Met + Met/Val vs. Val/Val: $P=0.023 ;$ Table III)

The junior 5-HTTLPR low and intermediate groups (HA: $10.9 \pm 5.4, n=63$ ) had lower total HA compared to the 5-HTTLPR high group (HA: $15.3 \pm 5.7, n=12$, low + intermediate vs. high: $P=0.009)$. Of the HA subscales, the junior 5HTTLPR low and intermediate groups (HA1: $3.4 \pm 2.1, n=66$; HA2: $2.4 \pm 1.7$, n=66) had lower HA1 ("anticipatory worry") and HA2 ("fear of uncertainty") compared to the high 5-HTTLPR group (HA1: $4.8 \pm 2.5 \mathrm{n}=12$, low + 


\section{Table III}

The mean novelty seeking (NS), harm avoidance (HA), and reward dependence (RD) dimension and subscale scores, as measured by the Tridimensional Personality Questionnaire (TPQ), for South African White participants in the combined COMT rs4680 Met/Met and Met/Val or the Val/Val genotype groups and in the 5-HTTLPR, in conjunction with SLC6A4 rs25531, low $\left(\mathrm{S}_{A} / \mathrm{S}_{A}\right)$ and intermediate $\left(\mathrm{S}_{A} / \mathrm{L}_{A}, \mathrm{~S}_{A} / \mathrm{L}_{\mathrm{G}}, \mathrm{L}_{A} / \mathrm{L}_{\mathrm{G}}, \mathrm{L}_{\mathrm{G}} / \mathrm{L}_{\mathrm{G}}\right)$ or High $\left(\mathrm{L}_{A} / \mathrm{L}_{A}\right)$ genotype group.

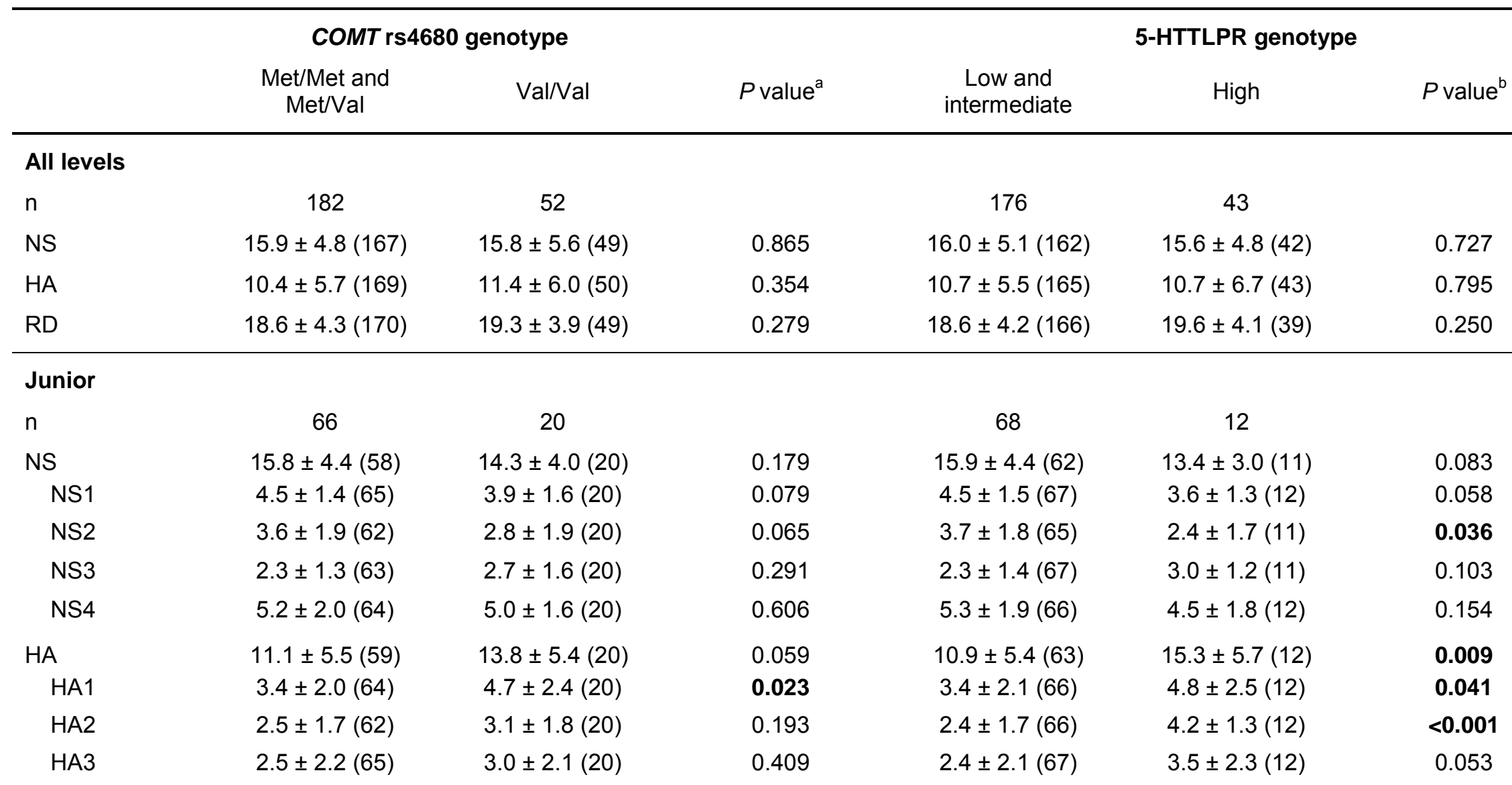




\begin{tabular}{lcccccc} 
HA4 & $2.9 \pm 2.4(64)$ & $3.1 \pm 2.1(20)$ & 0.794 & $2.9 \pm 2.3(66)$ & $2.8 \pm 2.4(12)$ & 0.994 \\
RD & $17.4 \pm 4.3(59)$ & $19.3 \pm 4.2(20)$ & 0.101 & $17.6 \pm 4.4(61)$ & $18.9 \pm 3.7(11)$ & 0.296 \\
\hline Senior & 116 & 32 & & 109 & 32 & \\
$\mathrm{n}$ & $16.0 \pm 5.1(109)$ & $16.9 \pm 6.3(29)$ & 0.482 & $16.1 \pm 5.5(100)$ & $16.4 \pm 5.1(31)$ & 0.618 \\
$\mathrm{NS}$ & $10.0 \pm 5.8(110)$ & $9.8 \pm 5.9(30)$ & 0.787 & $10.6 \pm 5.6(102)$ & $8.9 \pm 6.2(31)$ & 0.186 \\
HA & $19.3 \pm 4.2(111)$ & $19.3 \pm 3.8(29)$ & 0.957 & $19.2 \pm 4.0(105)$ & $19.8 \pm 4.3(28)$ & 0.485 \\
RD & & & & & & \\
\hline
\end{tabular}

Data are expressed as mean \pm standard deviation with the number of participants with non-missing data $(\mathrm{n})$ in parentheses. Age-adjusted $P$ values are displayed for ${ }^{a}$ Val/Val vs. Met/Met + Met/Val and ${ }^{b}$ low $\left(S_{A} S_{A}\right)+$ intermediate $\left(S_{A} L_{A}, S_{A} L_{G}, L_{A} L_{G}, L_{G} L_{G}\right)$ vs. high $\left(L_{A} L_{A}\right)$ genotype groups. Statistically significant differences $(P<0.05)$ are displayed in bold. NS1: exploratory excitability; NS2: impulsiveness; NS3: extravagance; NS4: disorderliness; HA1: anticipatory worry; HA2: fear of uncertainty; HA3: shyness/shyness with strangers; HA4: fatigability and asthenia. 
intermediate vs. high: $P=0.041$; HA2: $4.2 \pm 1.3, \mathrm{n}=12$, low + intermediate vs. high: $P<0.001$; Table III).

Senior. There were no differences in TPQ dimensions between the COMT rs4680 (NS: $P=0.482 ; \mathrm{HA}: P=0.787$; RD: $P=0.101$ ) and 5-HTTLPR (NS: $P=0.618$; HA: $P=0.186$; RD: $P=0.485$; Table III) genotype groups in the senior cohort.

\section{TPQ and concussion history}

All levels. TPQ scores were similar between the control and case groups when junior and senior levels of play were combined (case all: NS: $P=0.598$; HA: $P=0.348$; RD: $P=0.951$; case diagnosed only: NS: $P=0.763$; HA: $P=0.481$; RD: $P=0.485$; Table IV).

Junior. The junior control group (HA: $12.9 \pm 5.8, \mathrm{n}=46)$ had higher HA than the junior case (all) (HA: $9.7 \pm 5.0, n=39, P=0.007)$ and junior case (diagnosed only) groups (HA: $9.5 \pm 4.8, n=31, P=0.004$; Table IV). Specifically, the HA subscales HA1 ("anticipatory worry") and HA2 ("fear of uncertainty") were higher in the junior control group (HA1: $4.1 \pm 2.2, n=49$; HA2: $3.0 \pm 1.9, n=48$ ) than junior case (all) (HA1: $3.0 \pm 1.9, \mathrm{n}=41, P=0.016$; HA2: $2.1 \pm 1.5, \mathrm{n}=40$, $P=0.013)$ and junior case (diagnosed only) groups (HA1: $2.9 \pm 1.7, n=33$, $P=0.008 ;$ HA2: $1.9 \pm 1.4, \mathrm{n}=32, P=0.006$; Table IV). There were no differences between junior control and case groups in NS or RD (case all: NS: 


\section{Table IV}

The Tridimensional Personality Questionnaire dimension scores, novelty seeking (NS), harm avoidance (HA), reward dependence (RD), of junior (high school) and senior (senior amateur club and professional players) rugby players without a previous suspected or diagnosed concussion (control), with a minimum of one suspected or diagnosed concussion (case all), and additionally case (all) participants with one or more diagnosed concussions (case diagnosed only).

Data are expressed as mean \pm standard deviation with the number of participants with non-

\begin{tabular}{|c|c|c|c|c|c|}
\hline Level of play & Control & Case (all) & $\begin{array}{c}P \\
\text { value }^{a}\end{array}$ & $\begin{array}{c}\text { Case } \\
\text { (diagnosed } \\
\text { only) }\end{array}$ & $\underset{\text { value }^{\text {b }}}{P}$ \\
\hline \multicolumn{6}{|l|}{ All Levels } \\
\hline $\mathrm{n}$ & 140 & 163 & & 140 & \\
\hline NS & $16.1 \pm 5.2(100)$ & $15.6 \pm 4.9(122)$ & 0.598 & $15.8 \pm 4.9(103)$ & 0.763 \\
\hline $\mathrm{HA}$ & $10.3 \pm 5.8(102)$ & $10.7 \pm 5.8(125)$ & 0.348 & $10.6 \pm 5.7(105)$ & 0.481 \\
\hline $\mathrm{RD}$ & $18.7 \pm 4.0$ & $18.8 \pm 4.4(127)$ & 0.951 & $19.2 \pm 4.2(109)$ & 0.485 \\
\hline \multicolumn{6}{|l|}{ Junior } \\
\hline $\mathrm{n}$ & 74 & 63 & & 53 & \\
\hline NS & $15.4 \pm 4.7(46)$ & $15.3 \pm 3.9(37)$ & 0.901 & $15.2 \pm 3.9(30)$ & 0.825 \\
\hline $\mathrm{HA}$ & $12.9 \pm 5.8(46)$ & $9.7 \pm 5.0(39)$ & 0.007 & $9.5 \pm 4.8(31)$ & 0.004 \\
\hline HA1 & $4.1 \pm 2.2(49)$ & $3.0 \pm 1.9(41)$ & 0.016 & $2.9 \pm 1.7(33)$ & 0.008 \\
\hline $\mathrm{HA} 2$ & $3.0 \pm 1.9(48)$ & $2.1 \pm 1.5(40)$ & 0.013 & $1.9 \pm 1.4(32)$ & 0.006 \\
\hline HA3 & $2.9 \pm 2.2(49)$ & $2.3 \pm 2.0$ & 0.106 & $2.4 \pm 2.1$ & 0.149 \\
\hline HA4 & $3.1 \pm 2.3(49)$ & $2.5 \pm 2.3(41)$ & 0.244 & $2.5 \pm 2.3(33)$ & 0.228 \\
\hline $\mathrm{RD}$ & $17.7 \pm 3.9(44)$ & $18.2 \pm 4.9(40)$ & 0.770 & $18.7 \pm 4.9(33)$ & 0.423 \\
\hline \multicolumn{6}{|l|}{ Senior } \\
\hline $\mathrm{n}$ & 66 & 100 & & 87 & \\
\hline NS & $16.6 \pm 5.6(54)$ & $15.7 \pm 5.3(85)$ & 0.481 & $16.0 \pm 7.3(73)$ & 0.651 \\
\hline $\mathrm{HA}$ & $8.1 \pm 4.9(56)$ & $11.2 \pm 6.0(86)$ & $<0.001$ & $11.1 \pm 5.9(74)$ & 0.002 \\
\hline HA1 & $2.1 \pm 1.7(57)$ & $3.1 \pm 2.1(89)$ & 0.003 & $3.1 \pm 2.1(76)$ & 0.004 \\
\hline $\mathrm{HA} 2$ & $2.0 \pm 1.9(58)$ & $2.5 \pm 1.7(91)$ & 0.103 & $2.4 \pm 1.6(78)$ & 0.263 \\
\hline HA3 & $1.8 \pm 1.7(59)$ & $2.6 \pm 2.1(89)$ & 0.018 & $2.5 \pm 2.1(77)$ & 0.038 \\
\hline HA4 & $2.1 \pm 2.1(58)$ & $3.0 \pm 2.4(90)$ & 0.004 & $3.1 \pm 2.3(77)$ & 0.004 \\
\hline $\mathrm{RD}$ & $19.5 \pm 4.0(55)$ & $19.1 \pm 4.2(87)$ & 0.654 & $19.5 \pm 4.0(76)$ & 0.955 \\
\hline
\end{tabular}


$P=0.901$; RD: $P=0.770$; case diagnosed only: NS: $P=0.825$; RD: $P=0.423$; Table IV).

Senior. Conversely, the senior control group (HA: $8.1 \pm 4.9, n=56)$ had lower HA compared to senior case (all) (HA: $11.2 \pm 6.0, \mathrm{n}=86, P<0.001)$ and senior case (diagnosed only) (HA: $11.1 \pm 5.9, n=74, P=0.002)$ groups, with HA subscales HA1 ("anticipatory worry"), HA3 ("shyness/shyness with strangers"), and HA4 ("fatigability and asthenia") also being significantly lower in the senior control group (HA1: $2.1 \pm 1.7, n=57$; HA3: $1.8 \pm 1.7, n=59$; HA4: $2.1 \pm 2.1, \mathrm{n}=58$ ) than the senior case (all) (HA1: $3.1 \pm 2.1, \mathrm{n}=89, P=0.003$; HA3: $2.6 \pm 2.1, \mathrm{n}=89, P=0.018$; HA4: $3.0 \pm 2.4, \mathrm{n}=90, P=0.004$ ) and senior case (diagnosed only) groups (HA1: $3.1 \pm 2.1, \mathrm{n}=76, P=004$; HA3: $2.5 \pm 2.1$, $\mathrm{n}=77, P=0.038 ;$ HA4: $3.1 \pm 2.3, \mathrm{n}=77, P=0.004$, Table IV). NS and RD were similar between senior control and case groups (case all: NS: $P=0.481$; RD: $P=0.654$; case diagnosed only: NS: $P=0.651 ; \mathrm{RD}: P=0.955$; Table IV).

\section{Modeling the collective relationship between COMT rs4680 genotype, concussion history, and TPQ scores}

Generalized structural equation modeling was used to evaluate the collective relationship between specific genotypes (COMT rs4680 or 5-HTTLPR), concussion history (control versus case all; control versus case diagnosed only), and personality traits (NS, HA, and RD). Due to the previous significant associations observed in this study regarding $\mathrm{HA}$, the relationship between 
concussion history, genotype, and HA personality scores will be reported, while all modeling results are displayed in Supplementary tables SI and SII.

All levels. When all participants were evaluated, there was a significant association between COMT rs4680 genotypes and concussion history, while no other associations were noted (Figure 3, Supplementary table SI). Specifically, the COMT rs4680 Met/Val genotype was associated with concussion history, compared to the $\mathrm{Val} / \mathrm{Val}$ genotype, when comparing the control group to the case (all) (Met/Val vs. Val/Val: $P=0.049$, coefficient: 0.72 , SE: 0.36) and case (diagnosed only) groups (Met/Val vs. Val/Val: $P=0.047$, coefficient: 0.75 , SE: 0.38; Figure 3).

Junior. When only the juniors were examined, HA was associated with concussion history, but no other significant findings were noted (Figure 3, Supplementary table SI). HA differed between the junior control and the case group (all) (control vs. case all: $P=0.027$, coefficient: -0.11 , SE: 0.05 ) and case (diagnosed only) subgroup (control vs. case diagnosed only: $P=0.026$, coefficient: -0.12, SE: 0.06; Figure 3).

Senior. Significant associations were found between the HA and concussion history, however, no other associations were recorded in the senior cohort (Figure 3, Supplementary table SI). Specifically, HA was significantly different between the senior control and the senior case (all) group (control vs. case all: $P=0.005$, coefficient: 0.10 , SE: 0.04 ) and case (diagnosed only) subgroup 


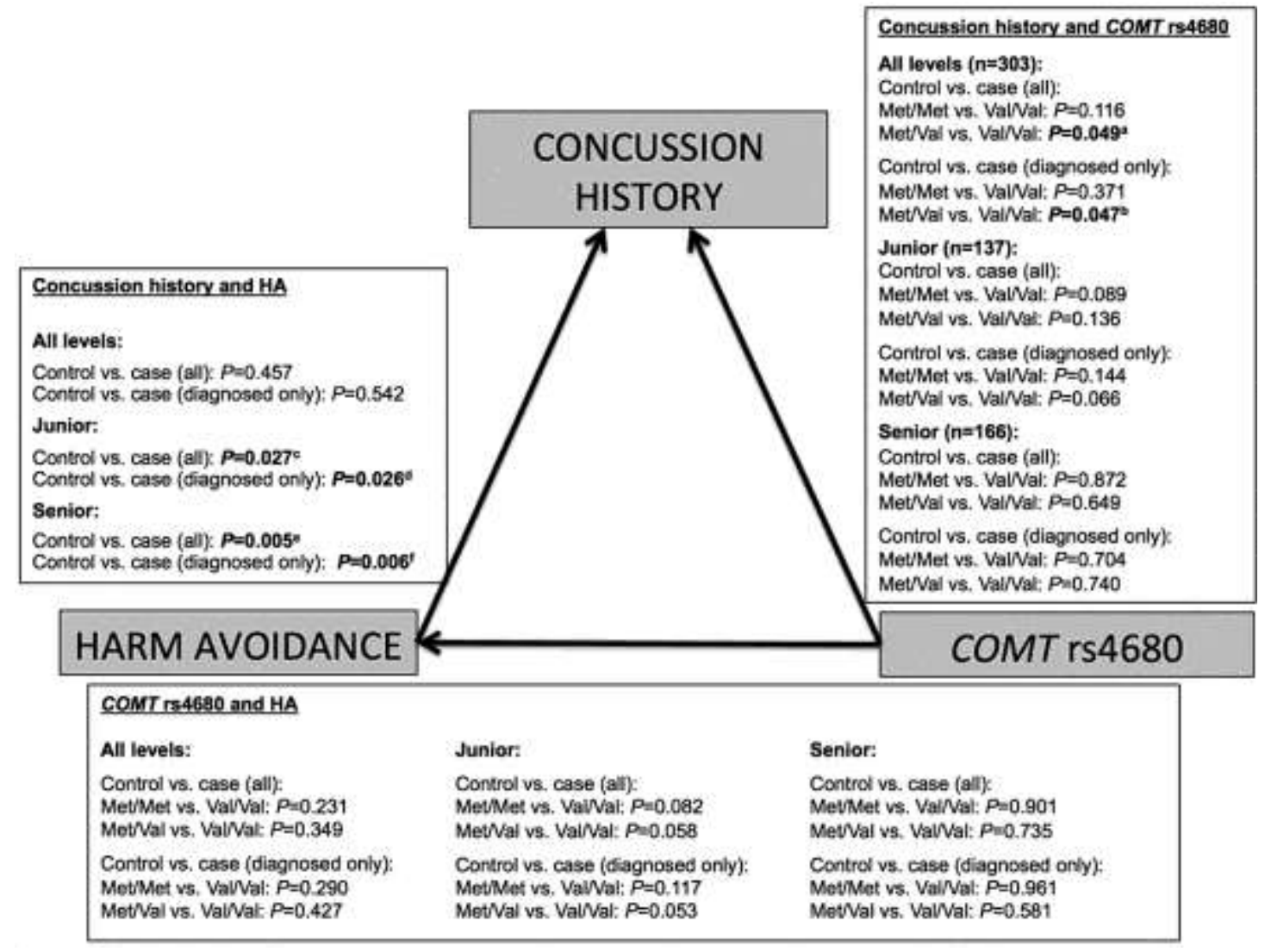

Figure 3: The results of the generalized structural equation model analysis that assessed the collective relationship between COMT rs4680 Val>Met genotype, concussion history, and harm avoidance $(\mathrm{HA})$ personality trait scores in South African rugby players without a previous diagnosed or suspected concussion (control), with a diagnosed or suspected concussion (case all), and additionally case (all) participants with a diagnosed concussion (case diagnosed only). Separate models were constructed for the control versus case (all) group and the control group versus the case (diagnosed only) subgroup in each level of play (junior: high school rugby players; senior: senior community-level amateur and senior professional rugby players; all levels: junior and senior rugby players). The COMT rs4680 Met/Val genotype was associated with concussion history, compared to the Val/Val genotype in all levels of play, when ${ }^{a}$ the control group was compared to the case (all) group (Met/Val vs. Val/Val: $P=0.049$, coefficient: 0.72, SE: 0.36) and ${ }^{b}$ when the control group was compared to the case (diagnosed only) subgroup

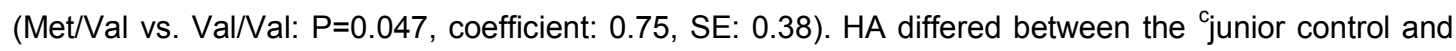
case (all) group ( $P=0.027$, coefficient: -0.11 , SE: 0.05$)$, ${ }^{d}$ the junior control and case (diagnosed only) subgroup ( $P=0.026$, coefficient: -0.12 , SE: 0.06$)$, ${ }^{e}$ the senior control and case (all) group $(P=0.005$, coefficient: $0.10, \mathrm{SE}: 0.04)$, and the senior control and case (diagnosed only) subgroup $(P=0.006$, coefficient: 0.11, SE: 0.04). SE: standard error 
(control vs. case diagnosed only: $P=0.006$, coefficient: $0.11, \mathrm{SE}: 0.04$; Figure 3).

Modeling the collective relationship between 5-HTTLPR genotype, concussion history, and TPQ scores

All levels. When all levels of play were combined, there were significant associations between 5-HTTLPR genotype groups and concussion history, whilst no associations were noted (Figure 4, Supplementary table SII). The 5HTTLPR intermediate (low vs. intermediate: $P=0.011$, coefficient: -1.06 , SE: 0.42 ) and high (low vs. high: $P=0.042$, coefficient: -1.01 , SE: 0.50 ) groups were associated with concussion history, compared to the low genotype group, but only when the control group was compared to the case (diagnosed only) subgroup (Figure 4).

Junior. In the junior cohort, HA differed between concussion history groups and the 5-HTTLPR genotype was associated with HA, but no significant associations were noted between 5-HTTLPR genotype and concussion history (Figure 4, Supplementary table SII). Specifically, the junior 5-HTTLPR high group was associated with HA compared to the 5-HTTLPR low group (control vs. case all, low vs. high: $P=0.043$, coefficient: $4.20, S E: 2.08$; control vs. case diagnosed only, low vs. high: $P=0.028$, coefficient: 4.62 , SE: 2.10 ; Figure 4). HA was significantly different between the junior control and case (diagnosed only) subgroup ( $P=0.049$, coefficient: -0.12 , SE: 0.06; Figure 4). 


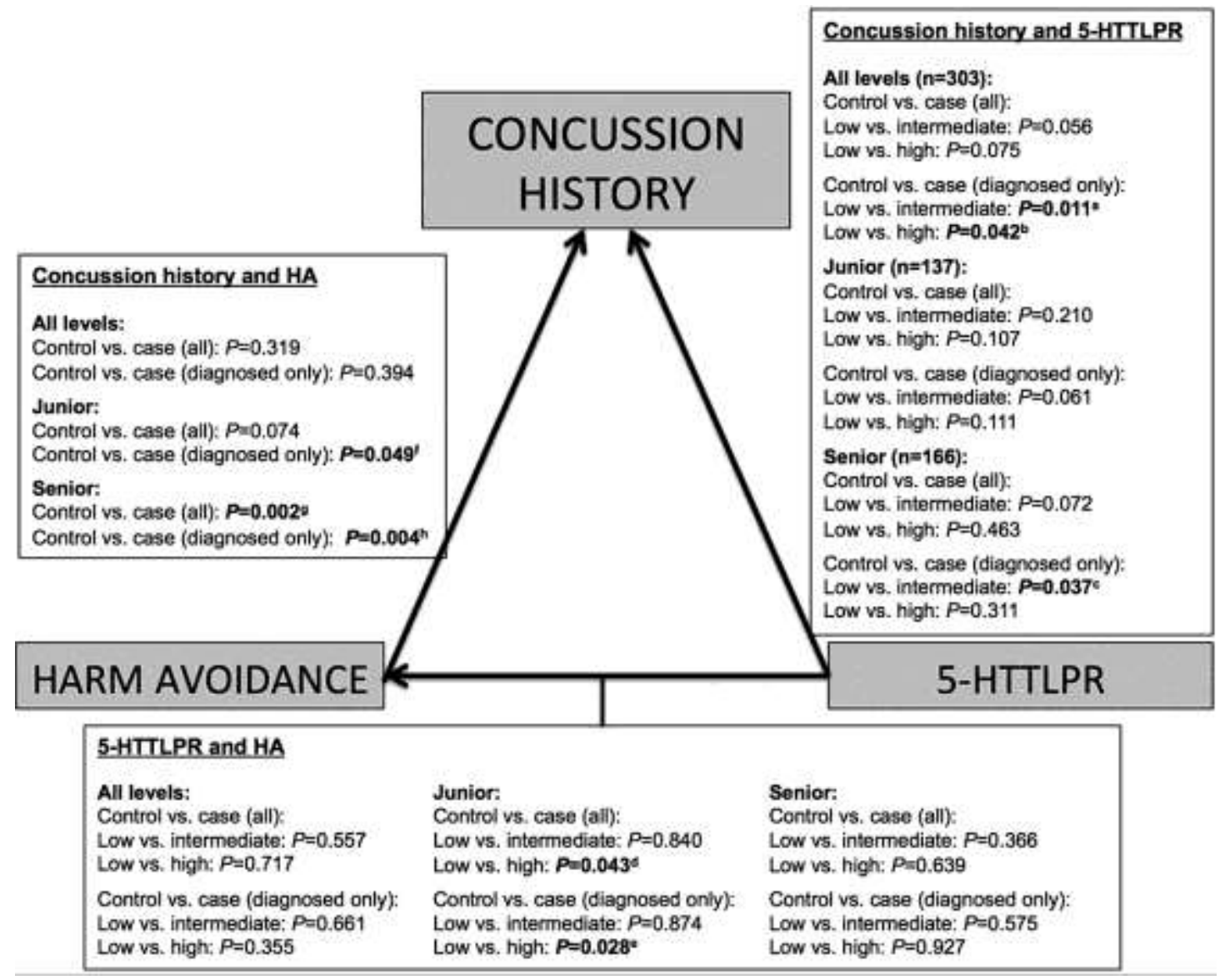

Figure 4: The summarized results of the generalized structural equation model analysis that assessed the collective relationship between serotonin-transporter-linked polymorphic region (5-HTTLPR), in conjunction with SLC6A4 rs25531, genotype groups ("low": $S_{A} / S_{A}$; "intermediate": $S_{A} / L_{A}, S_{A} / L_{G}, L_{A} / L_{G}$, $L_{G} / L_{G}$; "high": $\left.L_{A} / L_{A}\right)$, concussion history, and harm avoidance $(H A)$ personality trait scores in South African rugby players without a previous diagnosed or suspected concussion (control), with either a diagnosed or suspected concussion (case all), and case (all) participants with diagnosed concussions (case diagnosed only). Separate models were constructed for the control versus case (all) group and the control group versus the case (diagnosed only) subgroup in each level of play (junior: high school rugby players; senior: senior amateur and senior professional rugby players; all levels: junior and senior rugby players). When the control group was compared to the case (diagnosed only) subgroup in all levels of play, the 5-HTTLPR ${ }^{a}$ intermediate (low vs. intermediate: $P=0.011$, coefficient: $-1.06, S E: 0.42$ ) and ${ }^{b}$ high (low vs. high: $P=0.042$, coefficient: -1.01 , SE: 0.50 ) groups were associated with concussion history. ${ }^{\mathrm{C}}$ The 5 -HTTLPR intermediate group was associated with concussion history when the control group was compared to the case (diagnosed only) subgroup in the senior cohort (low vs. intermediate: $\mathrm{P}=0.037$, coefficient: -1.19 , SE: 0.57 ). The junior 5-HTTLPR high group was associated with HA, compared to the 5-HTTLPR low group, when the junior control group was compared to the junior ${ }^{d}$ case (all) (low vs. high: $\mathrm{P}=0.043$, coefficient: 4.20 , SE: 2.08 ) and ${ }^{\mathrm{e}}$ case (diagnosed only) subgroup (low vs. 
high: $P=0.028$, coefficient: $4.62, S E: 2.10)$. HA was significantly different between the junior control and case (diagnosed only) subgroup ( $P=0.049$, coefficient: -0.12 , SE: 0.06 ), the senior control and ${ }^{9}$ case (all) group ( $P=0.004$, coefficient: 0.12 , SE: 0.04 ), and the senior control and case (diagnosed only) subgroup ( $P=0.002$, coefficient: 0.12 , SE: 0.04). SE: standard error.

Senior. In the senior cohort, 5-HTTLPR and HA were both associated with concussion history, but there were no significant associations between 5HTTLPR genotypes and HA (Figure 4, Supplementary table SII). The 5HTTLPR intermediate group was associated with concussion history only when the control group was compared to the case (diagnosed only) subgroup in the senior cohort (low vs. intermediate: $P=0.037$, coefficient: -1.19 , SE: 0.57; Figure 4). HA was significantly different between the senior control and the case (all) ( $P=0.004$, coefficient: 0.12 , SE: 0.04$)$ and case (diagnosed only) subgroup ( $P=0.002$, coefficient: 0.12 , SE: 0.04; Figure 4$)$.

\section{Discussion}

The main finding of this study was that the COMT rs4680 Val>Met and the 5HTTLPR genotype frequencies significantly differed, both independently and as an inferred allele construct, between concussion history groups. Specifically, the COMT rs4680 Met allele carriers (Met/Met and Met/Val genotypes) and the low expressing 5-HTTLPR genotype group $\left(\mathrm{S}_{A} / \mathrm{S}_{A}\right.$ genotype) were twice as likely to have a history of concussion compared to other genotypes. In addition, the Met-S $\mathrm{A}_{\mathrm{A}}$ COMT-SLC6A4 inferred allele construct was over-represented in those with a concussion history. Similar genetic associations were noted in the junior, but not senior cohorts. 
When junior and senior participants were combined there were no associations between personality traits and concussion history groups. However, when splitting the participants by level of play, the junior case groups displayed significantly lower HA scores than the junior control group. There is emerging evidence linking increased risk-taking behaviour and lower injury risk appraisal to heightened injury susceptibility in sport. A recent study of over 1200 college students found that athletes with a previous concussion had higher risk-taking impulsivity and sensation seeking trait scores (Beidler, 2016). Specifically in rugby, players with high impulsivity measures also had increased rates of concussion (Hollis et al., 2009). In the present cohort, junior players with a concussion history had significantly lower HA scores, indicative of decreased risk appraisal. Lower levels of risk appraisal have been shown to result in increased risk-taking and impulsive behavior (Morrongiello \& Matheis, 2007; Siegel et al., 1994). It is therefore reasonable to propose that increased risk-taking behaviour, due to low risk appraisal or elevated impulsivity, may lead to heightened concussion risk in the junior rugby participants.

The senior case groups exhibited higher HA scores compared to the senior control group, in contrast to the findings in the junior cohort. Furthermore, the associations between genotypes and concussion history were largely absent in this cohort. Personality traits strongly influence the choice of recreational activities in adulthood (Gomà-i-Freixanet, Martha, \& Muro, 2012). Therefore at the senior level, where rugby participation is more of a personal preference, individuals with high risk appraisal may represent a 
natural, self selective exclusion from the cohort, reducing the chance of associations. Furthermore, the senior cohort included professional players and it may be argued at the elite level personality traits may have a very low influence on the style of play or subsequent injury risk. However, the sample size of this study is a limitation particularly when the cohorts were stratified by age. Further investigation is thus required to understand the conflicting findings between the levels of play.

In this study, the COMT rs4680 Met/Met and Met/Val participants were 2 and 3.6 times more likely to report a previous concussion when all levels of play were combined and in the junior cohort, respectively. In addition, there was a general linear trend for the frequency of the Met allele carriers to increase across those reporting zero, one, or two or more concussions. In the model analysis, which collectively assessed the relationships between COMT genotype, concussion history, and personality scores, the Met/Val genotype was associated with concussion, compared to the Val/Val genotype, but only when all levels of play were combined.

Elevated dopamine signaling is proposed to increase impulsive (Dalley \& Roiser, 2012; Pine et al., 2010) and risk-taking (Riba et al., 2008) traits and therefore the Met allele, with decreased dopamine clearance, should theoretically be linked to greater impulsivity and risk-taking. In support, the Met allele was previously associated with higher risk taking propensity (Amstadter et al., 2012), and elevated self-reported impulsivity scores (SoeiroDe-Souza et al., 2013) in healthy adults. Hence, the increased concussion susceptibility in COMT rs4680 Met carriers may possibly be due to increased 
risk-taking and impulsive traits, which have previously been suggested to increase concussion susceptibility in sport (Beidler, 2016; Hollis et al., 2009).

The associations between the COMT rs4680 and the personality traits measured in this study were inconsistent across the levels of play, with an absence of significant findings outside of the junior cohort and in the modeling analysis. The junior Met allele carriers tended to have lower total HA and had significantly lower "anticipatory worry" (HA1) compared to the junior Val/Val genotype, suggesting that the junior Met carriers may have decreased risk appraisal, which has been linked to risk-taking behaviour (Morrongiello \& Matheis, 2007; Siegel et al., 1994). Previous studies have implicated both the Val (C. Chen et al., 2011; Kim, Kim, Kim, Lee, \& Kim, 2006) and the Met (Enoch, Xu, Ferro, Harris, \& Goldman, 2003; Hashimoto, Noguchi, Hori, \& Ohi, 2007) allele with increased HA scores. The variability in the previously reported associations is supposedly due to differences in sex, ethnicity, preexisting diagnosis, and sample size between study populations (C. Chen et al., 2011; Montag et al., 2012). Therefore, the findings of the study need to be interpreted with caution until further research has comprehensively established, firstly, the role of COMT rs4680 on HA, impulsive, and risk-taking traits, and secondly, whether the COMT rs4680 SNP influences behaviours leading to concussion on the rugby field.

In addition to the COMT rs4680 polymorphism, the 5-HTTLPR genotypes also differed between concussion history groups. The 5-HTTLPR low groups were 2 and 3.4 times more likely to have a history of concussion 
when in all participants were combined and in the junior cohort, respectively. In partial support, the modeling analysis found significant associations between the 5-HTTLPR intermediate and high genotype groups with diagnosed concussion history in all levels of play, but not in the junior cohort.

The 5-HTTLPR S allele has been linked to higher levels of impulsive and risk-taking behaviours in a number of studies (Aluja, Garcia, Blanch, De Lorenzo, \& Fibla, 2009; Hallikainen et al., 1999; Kogan et al., 2010; Paaver et al., 2007; Paaver, Kurrikoff, Nordquist, Oreland, \& Harro, 2008; Sonuga-Barke et al., 2011; Walderhaug et al., 2010). Therefore, there is evidence that the $S_{A} / S_{A}$ homozygous participants, that comprise the low expressing 5-HTTLPR group, may exhibit higher impulsive or risk-taking behaviours. Following on, it may thus be plausible that, similar to COMT rs 4680 , the increased concussion susceptibility observed in the 5-HTTLPR low genotype group may be related to increased risk-taking and impulsive behaviours. Although it must be noted that several studies have also failed to show a relationship between 5HTTLPR and impulsivity (Lage et al., 2011; Malloy-Diniz et al., 2011; Patkar et al., 2002).

The associations between 5-HTTLPR and HA were only evident in the junior cohort. Specifically, the combined low and intermediate 5-HTTLPR genotype groups had lower total HA, "anticipatory worry", and "fear of uncertainty", while the collective modeling analysis associated the junior 5HTTLPR high ( $L_{A} / L_{A}$ genotype) group with HA compared to the 5-HTTLPR low genotype group. These associations suggest that junior carriers of the $S_{A}$ 
allele may have had lower risk appraisal. However, the absence of significant findings across all levels of play requires these results to be interpreted cautiously.

The association between the low 5-HTTLPR group and increased HA appears to be is in contrast with the previous evidence. Six meta-analysis studies have investigated the relationship between 5-HTTLPR and HA. Three found a significant association between the $S$ or $S_{A}$ allele and increased HA (Minelli, Bonvicini, Scassellati, Sartori, \& Gennarelli, 2011; Munafò et al., 2003; Munafò, Clark, \& Flint, 2005), while the remaining studies found no significant relationships (Munafo et al., 2009; Schinka, Busch, \& RobichauxKeene, 2004; Sen, Burmeister, \& Ghosh, 2004). The exact reasons for the contrasting findings are unknown, but previous inconsistencies between studies have been attributed to sample heterogeneity, small sample sizes, population stratification effects, the incorporation of the SLC6A4 rs25531 SNP, and comorbid psychiatric or medical diagnosis (Balestri et al., 2014). Therefore, similar to COMT rs4680, the findings regarding 5-HTTLPR needs to be interpreted with caution until further research has more thoroughly established whether, or how, the 5-HTTLPR might affect personality traits, rugby-related behaviours, and concussion susceptibility in rugby players.

Although this study highlighted novel genetic associations with concussion, there were several limitations. The main limitation was that the concussion history was self-reported. Several external factors, including concussion knowledge, attitudes, and age (Register-Mihalik et al., 2013), may 
influence concussion reporting. Future studies should implement a large-scale prospective design with medical doctor confirmed diagnosis. In addition, the study did not directly measure rugby-specific behaviors and therefore investigation is still required to identify whether, or how, the COMT rs4680 and 5-HTTLPR genotypes affect playing style on the rugby field, and to what extent risky or dangerous behavior contributes to concussion in rugby.

Overall, the study findings suggest that concussion risk in rugby may be modulated by personality traits and personality-associated genetic polymorphisms. Specifically, we hypothesize that junior rugby players with lower HA scores may more easily partake risky or dangerous play, while individuals with high HA may be more cautious, thereby reducing their exposure to possible concussion causing impacts. Education interventions highlighting the risks of reckless or dangerous play may therefore be beneficial to combat concussion, especially in youth rugby. Furthermore, rule changes aimed to limit aggressive and reckless play in ice hockey were found to reduce injury rates by 3 to 12 fold (Cusimano, Nastis, \& Zuccaro, 2012), and hence may also be beneficial in rugby to discourage risky play and thereby possibly reduce concussions. On an individual level, coaches and medical staff should aim to assess whether personality traits, or dangerous on-field behaviours, are contributing to the heightened susceptibility of concussion observed in rugby players that sustain frequent concussions.

In conclusion, this study provided provisional evidence for two novel genetic risk factors for concussion and further implicated impulsive and risk- 
taking behaviours in concussion susceptibility. Further research is required to clarify the effect of COMT rs4680 and 5-HTTLPR on rugby specific

behaviours and their relation to concussion risk.

\section{Reference List}

Aluja, A., Garcia, L. F., Blanch, A., De Lorenzo, D., \& Fibla, J. (2009). Impulsive-disinhibited personality and serotonin transporter gene polymorphisms: Association study in an inmate's sample. Journal of Psychiatric Research, 43(10), 906-914. http://doi.org/10.1016/j.jpsychires.2008.11.008

Amstadter, A. B., MacPherson, L., Wang, F., Banducci, A. N., Reynolds, E. K., Potenza, M. N., ... Lejuez, C. W. (2012). The relationship between risk-taking propensity and the COMT Val 158Met polymorphism among early adolescents as a function of sex. Journal of Psychiatric Research, 46(7), 940-945. http://doi.org/10.1016/j.jpsychires.2012.04.010

Balestri, M., Calati, R., Serretti, A., \& De Ronchi, D. (2014). Genetic modulation of personality traits: a systematic review of the literature. International Clinical Psychopharmacology, 29, 1-15. http://doi.org/10.1097/YIC.0b013e328364590b

Baugh, C. M., Stamm, J. M., Riley, D. O., Gavett, B. E., Shenton, M. E., Lin, A., ... Stern, R. A. (2012). Chronic traumatic encephalopathy: neurodegeneration following repetitive concussive and subconcussive brain trauma. Brain Imaging Behav, 6(2), 244-54. http://doi.org/10.1007/s11682012-9164-5

Beidler, E. (2016). Exploring psychological variables between collegiate student-athletes with and without a history of sport-related concussion.

Bouchard, T. J. (1994). Genes, environment, and personality. Science, 264(5166), 1700-1701. http://doi.org/10.1126/science.8209250

Carver, C. S., \& Miller, C. J. (2006). Relations of serotonin function to personality: Current views and a key methodological issue. Psychiatry Research, 144(1), 1-15. http://doi.org/10.1016/j.psychres.2006.03.013

Chen, C., Chen, C., Moyzis, R., Dong, Q., He, Q., Zhu, B., ... Lessard, J. (2011). Sex modulates the associations between the COMT gene and personality traits. Neuropsychopharmacology, 36(8), 1593-8. http://doi.org/10.1038/npp.2011.39

Chen, J., Lipska, B. K., Halim, N., Ma, Q. D., Matsumoto, M., Melhem, S., ... Weinberger, D. R. (2004). Functional analysis of genetic variation in catechol-O-methyltransferase (COMT): effects on mRNA, protein, and enzyme activity in postmortem human brain. American Journal of Human Genetics, 75, 807-821. http://doi.org/10.1086/425589

Cloninger, C. R. (1986). A unified biosocial theory of personality and its role in the development of anxiety states. Psychiatric Developments, 4(3), 167-226.

Cloninger, C. R. (1987). A systematic method for clinical description and classification of personality variants: a proposal. Archives of General Psychiatry, 44(6), 573-588. http://doi.org/10.1001/archpsyc.1987.01800180093014

Cusimano, M. D., Nastis, S., \& Zuccaro, L. (2012). Effectiveness of Interventions to reduce aggression and injuries among ice hockey players: a systematic review. Canadian Medical Association Journal, cmaj-112017. http://doi.org/10.1503/cmaj

Dalley, J. W., \& Roiser, J. P. (2012). Dopamine, serotonin and impulsivity. Neuroscience, 215, 42-58. http://doi.org/10.1016/j.neuroscience.2012.03.065

Davidson, R. J. (2001). Toward a biology of personality and emotion. Annals of the New York Academy of Sciences, 935, 191-207. http://doi.org/10.1111/j.1749-6632.2001.tb03481.x

Enoch, M. A., Xu, K., Ferro, E., Harris, C. R., \& Goldman, D. (2003). Genetic origins of anxiety in women: a role for a functional catechol-O-methyltransferase polymorphism. Psychiatr Genet, 13. http://doi.org/10.1097/00041444-200303000-00006

Fraas, M. R., Coughlan, G. F., Hart, E. C., \& McCarthy, C. (2014). Concussion history and reporting rates in elite Irish rugby union players. Physical Therapy in Sport, 15(3), 136-142. http://doi.org/10.1016/j.ptsp.2013.08.002

Fresán, A., Robles-García, R., López-Avila, A., \& Cloninger, C. R. (2011). Personality differences according to age and sex in a Mexican sample using the Temperament and Character InventoryRevised. Comprehensive Psychiatry, 52(6), 774-779. http://doi.org/10.1016/j.comppsych.2010.11.003

Gerberich, S. G., Finke, R., Madden, M., Priest, J., Aamoth, G., \& Murray, K. (1987). An epidemiological study of high school ice hockey injuries. Childs Nerv Syst, 3(2), 59-64. http://doi.org/10.1007/BF00271123

Gomà-i-Freixanet, M., Martha, C., \& Muro, A. (2012). Does the Sensation-Seeking trait differ among 
participants engaged in sports with different levels of physical risk? Anales de Psicología, 28(1), 223-232. http://doi.org/hdl.handle.net/10201/26415

González, J. R., Armengol, L., Solé, X., Guinó, E., Mercader, J. M., Estivill, X., \& Moreno, V. (2007). SNPassoc: An R package to perform whole genome association studies. Bioinformatics, 23(5), 644-645. http://doi.org/10.1093/bioinformatics/btm025

Gouttebarge, V., Aoki, H., Lambert, M., Stewart, W., \& Kerkhoffs, G. (2017). A history of concussions is associated with symptoms of common mental disorders in former male professional athletes across a range of sports. British Journal of Sports Medicine, 51, 324. http://doi.org/10.1136/bjsports-2016-097372.104

Guskiewicz, K. M., Register-Mihalik, J., McCrory, P., McCrea, M., Johnston, K., Makdissi, M., ... Meeuwisse, W. (2013). Evidence-based approach to revising the SCAT2: introducing the SCAT3. British Journal of Sports Medicine, 47(5), 289-93. http://doi.org/10.1136/bjsports-2013-092225

Hallikainen, T., Saito, T., Lachman, H. M., Volavka, J., Pohjalainen, T., Ryynänen, O. P., ... Tiihonen, J. (1999). Association between low activity serotonin transporter promoter genotype and early onset alcoholism with habitual impulsive violent behavior. Molecular Psychiatry, 4(4), 385-388. http://doi.org/10.1038/sj.mp.4000526

Hashimoto, R., Noguchi, H., Hori, H., \& Ohi, K. (2007). A possible association between the Val158Met polymorphism of the catechol-O-methyl transferase gene and the personality trait of harm avoidance in Japanese healthy subjects. Psychiatry: Interpersonal and Biological Processes, 428, 17-20. http://doi.org/10.1016/j.neulet.2007.09.036

Heils, A., Teufel, A., Petri, S., Stöber, G., Riederer, P., Bengel, D., \& Lesch, K. P. (1996). Allelic variation of human serotonin transporter gene expression. Journal of Neurochemistry, 66(6), 2621-2624. http://doi.org/10.1046/j.1471-4159.1996.66062621.x

Hollis, S. J., Stevenson, M. R., Mclntosh, A. S., Shores, E. A., Collins, M. W., \& Taylor, C. B. (2009). Incidence, risk, and protective factors of mild traumatic brain injury in a cohort of Australian nonprofessional male rugby players. The American Journal of Sports Medicine, 37(12), 2328-33. http://doi.org/10.1177/0363546509341032

Hu, X., Lipsky, R. H., Zhu, G., Akhtar, L. A., Taubman, J., Greenberg, B. D., ... Goldman, D. (2006). Serotonin transporter promoter gain-of-function genotypes are linked to obsessive-compulsive disorder. The American Journal of Human Genetics, 78(5), 815-826.

Kennis, M., Rademaker, A. R., \& Geuze, E. (2013). Neural correlates of personality: An integrative review. Neuroscience and Biobehavioral Reviews, 37(1), 73-95. http://doi.org/10.1016/j.neubiorev.2012.10.012

Kerr, Z. Y., Evenson, K. R., Rosamond, W. D., Mihalik, J. P., Guskiewicz, K. M., \& Marshall, S. W. (2014). Association between concussion and mental health in former collegiate athletes. Injury Epidemiology, 1(1), 28. http://doi.org/10.1186/s40621-014-0028-x

Kim, S. J., Kim, Y. S., Kim, S. Y., Lee, H. S., \& Kim, C. (2006). An association study of catechol-Omethyltransferase and monoamine oxidase A polymorphisms and personality traits in Koreans. Neuroscience Letters, 401, 154-158. http://doi.org/10.1016/j.neulet.2006.03.006

Kogan, S. M., Beach, S. R. H., Philibert, R. a, Brody, G. H., Chen, Y.-F., \& Lei, M.-K. (2010). 5-HTTLPR status moderates the effect of early adolescent substance use on risky sexual behavior. Health Psychology, 29(5), 471-6. http://doi.org/10.1037/a0020594

Koh, J. O., Cassidy, J. D., \& Watkinson, E. J. (2003). Incidence of concussion in contact sports: a systematic review of the evidence. Brain Injury, 17(10), 901-917. http://doi.org/10.1080/0269905031000088869

Lage, G. M., Malloy-Diniz, L. F., Matos, L. O., Bastos, M. A. R., Abrantes, S. S. C., \& Corrêa, H. (2011) Impulsivity and the 5-HTTLPR polymorphism in a non-clinical sample. PLOS ONE, 6(2), 1-5. http://doi.org/10.1371/journal.pone.0016927

Lee, L., \& Prescott, C. (2014). Association of the Catechol-O-Methyltransferase (COMT) Val158Met polymorphism and anxiety-related traits: A meta-analysis. Psychiatric Genetics, 24(2), 52-69. http://doi.org/10.1016/j.biotechadv.2011.08.021.Secreted

Lesch, K. P., Bengel, D., Heils, A., Sabol, S. Z., Greenberg, B. D., Petri, S., ... Murphy, D. L. (1996). Association of anxiety-related traits with a polymorphism in the serotonin transporter gene regulatory region. Science, 274(5292), 1527-1531. http://doi.org/10.1126/science.274.5292.1527

Little, J., Higgins, J. P. T., loannidis, J. P. A., Moher, D., Gagnon, F., Von Elm, E., ... Birkett, N. (2009). STrengthening the REporting of genetic association studies (STREGA)- An extension of the STROBE statement. European Journal of Clinical Investigation, 39(4), 247-266. http://doi.org/10.1002/gepi.20410

Malloy-Diniz, L. F., Neves, F. S., De Moraes, P. H. P., De Marco, L. A., Romano-Silva, M. A., Krebs, M. O., \& Correa, H. (2011). The 5-HTTLPR polymorphism, impulsivity and suicide behavior in euthymic bipolar patients. Journal of Affective Disorders, 133(1-2), 221-226. http://doi.org/10.1016/j.jad.2011.03.051

Mc Fie, S., Brown, J., Hendricks, S., Posthumus, M., Readhead, C., Lambert, M., ... Viljoen, W. (2016). Incidence and factors associated with concussion injuries at the 2011 to 2014 South African Rugby Union Youth Week Tournaments. Clinical Journal of Sport Medicine, 26(5), 398-404. http://doi.org/10.1097/JSM.0000000000000276

McCrory, P., Meeuwisse, W. H., Aubry, M., Cantu, B., Dvorak, J., Echemendia, R., ... Turner, M. (2013). 
Consensus Statement on Concussion in Sport: The 4th International Conference on Concussion in Sport held in Zurich, November 2012. British Journal of Sports Medicine, 47(2), 250-258. http://doi.org/10.1136/bjsports-2013-092313

Mckee, A. C., Cantu, R. C., Nowinski, C. J., Hedley-whyte, T., Gavett, B. E., Budson, A. E., ... Stern, R. A. (2009). Chronic Traumatic Encephalopathy in athletes: progressive tauopathy following repetitive head injury. J Neuropathol Exp Neurol, 68(7), 709-735. http://doi.org/10.1097/NEN.0b013e3181a9d503.Chronic

Meyer-Lindenberg, A., Nichols, T., Callicott, J. H., Ding, J., Kolachana, B., Buckholtz, J., ... Weinberger, D. R. (2006). Impact of complex genetic variation in COMT on human brain function. Molecular Psychiatry, 11, 867-877, 797. http://doi.org/10.1038/sj.mp.4001860

Minelli, A., Bonvicini, C., Scassellati, C., Sartori, R., \& Gennarelli, M. (2011). The influence of psychiatric screening in healthy populations selection: a new study and meta-analysis of functional 5HTTLPR and rs25531 polymorphisms and anxiety-related personality traits. BMC Psychiatry, 11(1), 50. http://doi.org/10.1186/1471-244X-11-50

Montag, C., Jurkiewicz, M., \& Reuter, M. (2012). The role of the Catechol-O-Methyltransferase (COMT) gene in personality and related psychopathological disorders. CNS \& Neurological Disorders Drug Targets, 11, 236-250. http://doi.org/10.2174/187152712800672382

Morrongiello, B. A., \& Matheis, S. (2007). Understanding children's injury-risk behaviors: The independent contributions of cognitions and emotions. Journal of Pediatric Psychology, 32(8), 926-937. http://doi.org/10.1093/jpepsy/jsm027

Munafò, M. R., Clark, T., \& Flint, J. (2005). Does measurement instrument moderate the association between the serotonin transporter gene and anxiety-related personality traits? A meta-analysis. Molecular Psychiatry, 10, 415-419. http://doi.org/10.1038/sj.mp.4001627

Munafò, M. R., Clark, T. G., Moore, L. R., Payne, E., Walton, R., \& Flint, J. (2003). Genetic polymorphisms and personality in healthy adults: a systematic review and meta-analysis. Molecular Psychiatry, 8(5), 471-84. http://doi.org/10.1038/sj.mp.4001326

Munafo, M. R., Freimer, N. B., Ng, W., Ophoff, R., Veijola, J., Miettunen, J., ... Flint, J. (2009). 5HTTLPR genotype and anxiety-related personality traits: A meta-analysis and new data. American Journal of Medical Genetics, Part B: Neuropsychiatric Genetics, 150(2), 271-281. http://doi.org/10.1002/ajmg.b.30808

Nordquist, N., \& Oreland, L. (2010). Serotonin, genetic variability, behaviour, and psychiatric disorders a review. Upsala Journal of Medical Sciences, 115(1), 2-10. http://doi.org/10.3109/03009730903573246

Paaver, M., Kurrikoff, T., Nordquist, N., Oreland, L., \& Harro, J. (2008). The effect of 5-HTT gene promoter polymorphism on impulsivity depends on family relations in girls. Progress in NeuroPsychopharmacology and Biological Psychiatry, 32(5), 1263-1268. http://doi.org/10.1016/j.pnpbp.2008.03.021

Paaver, M., Nordquist, N., Parik, J., Harro, M., Oreland, L., \& Harro, J. (2007). Platelet MAO activity and the 5-HTT gene promoter polymorphism are associated with impulsivity and cognitive style in visual information processing. Psychopharmacology, 194(4), 545-554. http://doi.org/10.1007/s00213-007-0867-z

Panenka, W., Gardner, A., Dretsch, M., Crynen, G., Crawford, F. C., \& Iverson, G. L. (2017). Systematic review of genetic risk factors for sustaining a mild traumatic brain injury. Journal of Neurotrauma, 33. http://doi.org/10.1089/neu.2016.4833

Patkar, A. A., Berrettini, W. H., Hoehe, M., Thornton, C. C., Gottheil, E., Hill, K., \& Weinstein, S. P. (2002). Serotonin transporter polymorphisms and measures of impulsivity, aggression, and sensation seeking among African-American cocaine-dependent individuals. Psychiatry Research, 110(2), 103-115. http://doi.org/10.1016/S0165-1781(02)00098-7

Pine, A., Shiner, T., Seymour, B., \& Dolan, R. J. (2010). Dopamine, time, and impulsivity in humans. The Journal of Neuroscience: The Official Journal of the Society for Neuroscience, 30(26), 888896. http://doi.org/10.1523/JNEUROSCI.6028-09.2010

R Core Team, R. (2013). R: A language and environment for statistical computing. R: A language and environment for statistical computing. Vienna, Austria: R Foundation for Statistical Computing.

Raftery, M. (2014). Concussion and chronic traumatic encephalopathy: International Rugby Board's response. British Journal of Sports Medicine, 48(2), 79-80. http://doi.org/10.1136/bjsports-2013093051

Register-Mihalik, J. K., Guskiewicz, K. M., McLeod, T. C. V., Linnan, L. A., Mueller, F. O., \& Marshall, S. W. (2013). Knowledge, attitude, and concussion-reporting behaviors among high school athletes: A preliminary study. Journal of Athletic Training, 48(5), 645-653. http://doi.org/10.4085/10626050-48.3.20

Riba, J., Krämer, U. M., Heldmann, M., Richter, S., \& Münte, T. F. (2008). Dopamine agonist increases risk taking but blunts reward-related brain activity. PLOS ONE, 3(6), 4-8. http://doi.org/10.1371/journal.pone.0002479

Schaid, D. J., Rowland, C. M., Tines, D. E., Jacobson, R. M., \& Poland, G. A. (2002). Score tests for association between traits and haplotypes when linkage phase is ambiguous. Am J Hum Genet, 70(2), 425-434. http://doi.org/10.1086/338688

Schinka, J. A., Busch, R. M., \& Robichaux-Keene, N. (2004). A meta-analysis of the association 
between the serotonin transporter gene polymorphism (5-HTTLPR) and trait anxiety. Molecular Psychiatry, 9(2), 197-202. http://doi.org/10.1038/sj.mp.4001405

Sen, S., Burmeister, M., \& Ghosh, D. (2004). Meta-analysis of the association between a serotonin transporter promoter polymorphism (5-HTTLPR) and anxiety-related personality traits. American Journal of Medical Genetics. Part B, Neuropsychiatric Genetics, 127B(September 2003), 85-89. http://doi.org/10.1002/ajmg.b.20158

Siegel, A. W., Cousins, J. H., Rubovits, D. S., Parsons, J. T., Lavery, B., \& Crowley, C. L. (1994). Adolescents' perceptions of the benefits and risks of their own risk taking. Journal of Emotional and Behavioral Disorders, 2(2), 89-98. http://doi.org/10.1177/106342669400200203

Soeiro-De-Souza, M. G., Stanford, M. S., Bio, D. S., Machado-Vieira, R., \& Moreno, R. A. (2013). Association of the COMT met158 allele with trait impulsivity in healthy young adults. Molecular Medicine Reports, 7, 1067-1072. http://doi.org/10.3892/mmr.2013.1336

Sonuga-Barke, E. J. S., Kumsta, R., Schlotz, W., Lasky-Su, J., Marco, R., Miranda, A., ... Faraone, S. $V$. (2011). A functional variant of the serotonin transporter gene (SLC6A4) moderates impulsive choice in attention-deficit/hyperactivity disorder boys and siblings. Biological Psychiatry, 70(3), 230-236. http://doi.org/10.1016/j.biopsych.2011.01.040

Stein, M. B., Fallin, M. D., Schork, N. J., \& Gelernter, J. (2005). COMT polymorphisms and anxietyrelated personality traits. Neuropsychopharmacology, 30(11), 2092-102. http://doi.org/10.1038/sj.npp.1300787

Stoltenberg, S. F., Lehmann, M. K., Anderson, C., Nag, P., \& Anagnopoulos, C. (2011). Serotonin transporter (5-HTTLPR) genotype and childhood trauma are associated with individual differences in decision making. Frontiers in Genetics, 2(JUNE), 1-9. http://doi.org/10.3389/fgene.2011.00033

Sye, G., Sullivan, S. J., \& McCrory, P. (2006). High school rugby players' understanding of concussion and return to play guidelines. British Journal of Sports Medicine, 40(12), 1003-5. http://doi.org/10.1136/bjsm.2005.020511

Thomas, D. C., \& Witte, J. S. (2001). Population Stratification: A problem for case-control studies of candidage-gene associations? Cancer Epidemiology, Biomarkers \& Prevention, 11, 505-512.

van Breda, K., Collins, M., Stein, D. J., \& Rauch, L. (2015). The COMT val158met polymorphism in ultra-endurance athletes. Physiology \& Behavior, 151, 279-283. http://doi.org/10.1016/j.physbeh.2015.07.039

Walderhaug, E., Herman, A. I., Magnusson, A., Morgan, M. J., \& Landro, N. I. (2010). The short (S) allele of the serotonin transporter polymorphism and acute tryptophan depletion both increase impulsivity in men. Neuroscience Letters, 473(3), 208-211. http://doi.org/10.1016/j.neulet.2010.02.048

Warnes, G., \& Leisch, F. (2006). Genetics: population genetics. R Package, version 1.2. 1.

Wendland, J. R., Martin, B. J., Kruse, M. R., Lesch, K.-P., \& Murphy, D. L. (2006). Simultaneous genotyping of four functional loci of human SLC6A4, with a reappraisal of 5-HTTLPR and rs25531. Molecular Psychiatry, 11, 224-226. http://doi.org/10.1038/sj.mp.4001789 


\section{Supplementary tables}

\section{Table SI:}

The results of the generalized structural equation model analysis that assessed the collective relationship between concussion history, novelty seeking (NS), harm avoidance (HA), and reward dependence (RD) personality scores, and COMT rs4680 Val>Met genotype in junior (high school) and senior (senior community-level amateur and senior professional) rugby participants without a previous suspected or diagnosed concussion (control) compared to those with a minimum of one suspected or diagnosed concussion (case all) or case (all) participants with one or more diagnosed concussions (case diagnosed only). Separate models were constructed for the control versus case (all) group (control vs. case all) and the control group compared to the case (diagnosed only) subgroup (control vs. case diagnosed only) in each level of play (all levels, junior, and senior).

\begin{tabular}{|c|c|c|c|c|c|c|c|c|c|}
\hline & & \multicolumn{4}{|c|}{ Control vs. case (all) } & \multicolumn{4}{|c|}{ Control vs. case (diagnosed only) } \\
\hline & & Coefficient & SE & $95 \% \mathrm{CI}$ & $P$ value & Coefficient & SE & $95 \% \mathrm{CI}$ & $P$ value \\
\hline \multicolumn{10}{|l|}{ All levels } \\
\hline \multicolumn{10}{|l|}{ NS } \\
\hline \multirow[t]{2}{*}{ COMT rs4680 } & Met/Val & -0.03 & 0.86 & -1.71 to 1.66 & 0.975 & 0.24 & 0.88 & -1.48 to 1.96 & 0.784 \\
\hline & Met/Met & 0.25 & 0.96 & -1.63 to 2.14 & 0.792 & 0.13 & 1.01 & -1.85 to 2.11 & 0.896 \\
\hline \multicolumn{10}{|l|}{ HA } \\
\hline \multirow[t]{2}{*}{ COMT rs 4680} & Met/Val & -0.92 & 0.99 & -2.86 to 1.01 & 0.349 & -0.80 & 1.01 & -2.77 to 1.17 & 0.427 \\
\hline & Met/Met & -1.30 & 1.09 & -3.44 to 0.83 & 0.231 & -1.21 & 1.14 & -3.44 to 1.03 & 0.290 \\
\hline \multicolumn{10}{|l|}{ RD } \\
\hline COMT rs 4680 & Met/Val & -0.60 & 0.73 & -2.02 to 0.83 & 0.414 & -0.57 & 0.73 & -2.00 to 0.85 & 0.430 \\
\hline
\end{tabular}




\begin{tabular}{|c|c|c|c|c|c|c|c|c|c|}
\hline & Met/Met & -0.79 & 0.81 & -3.44 to 0.83 & 0.329 & -0.50 & 0.83 & -2.12 to 1.12 & 0.543 \\
\hline \multicolumn{10}{|c|}{ Concussion history } \\
\hline NS & & -0.02 & 0.03 & -0.08 to 0.04 & 0.461 & -0.02 & 0.03 & -0.08 to 0.04 & 0.592 \\
\hline HA & & 0.02 & 0.03 & -0.03 to 0.07 & 0.457 & 0.02 & 0.03 & -0.04 to 0.07 & 0.542 \\
\hline $\mathrm{RD}$ & & 0.02 & 0.04 & -0.05 to 0.09 & 0.575 & 0.04 & 0.04 & -0.03 to 0.12 & 0.253 \\
\hline \multirow[t]{2}{*}{ COMT rs 4680} & Met/Val & 0.72 & 0.36 & 0.00 to 1.43 & 0.049 & 0.75 & 0.38 & 0.01 to 1.48 & 0.047 \\
\hline & Met/Met & 0.63 & 0.40 & -0.16 to 1.42 & 0.116 & 0.38 & 0.42 & -0.45 to 1.21 & 0.371 \\
\hline \multicolumn{10}{|l|}{ Junior } \\
\hline \multicolumn{10}{|l|}{ NS } \\
\hline \multirow[t]{2}{*}{ COMT rs 4680} & Met/Val & 1.40 & 1.18 & -0.92 to 3.72 & 0.237 & 1.60 & 1.21 & -0.78 to 3.97 & 0.188 \\
\hline & Met/Met & 1.57 & 1.32 & -1.01 to 4.15 & 0.234 & 1.29 & 1.40 & -1.46 to 4.04 & 0.359 \\
\hline \multicolumn{10}{|l|}{ HA } \\
\hline \multirow[t]{2}{*}{ COMT rs 4680} & Met/Val & -2.85 & 1.50 & -5.80 to 0.09 & 0.058 & -3.02 & 1.56 & -6.08 to 0.04 & 0.053 \\
\hline & Met/Met & -2.89 & 1.66 & -6.14 to 0.36 & 0.082 & -2.79 & 1.78 & -6.27 to 0.69 & 0.117 \\
\hline \multicolumn{10}{|l|}{ RD } \\
\hline \multirow[t]{2}{*}{ COMT rs 4680} & Met/Val & -2.27 & 1.18 & -4.50 to 0.03 & 0.053 & -2.37 & 1.20 & -4.72 to -0.03 & 0.047 \\
\hline & Met/Met & -0.95 & 1.30 & -3.49 to 1.59 & 0.462 & -1.16 & 1.36 & -3.83 to 1.51 & 0.395 \\
\hline \multicolumn{10}{|c|}{ Concussion history } \\
\hline NS & & -0.04 & 0.06 & -0.15 to 0.08 & 0.543 & -0.05 & 0.06 & -0.17 to 0.08 & 0.482 \\
\hline HA & & -0.11 & 0.05 & -0.22 to -0.01 & 0.027 & -0.12 & 0.06 & -0.23 to -0.01 & 0.026 \\
\hline RD & & 0.04 & 0.06 & -0.08 to 0.16 & 0.522 & 0.09 & 0.07 & -0.05 to 0.23 & 0.189 \\
\hline \multirow[t]{2}{*}{ COMT rs4680 } & Met/Val & 1.05 & 0.70 & -0.33 to 2.43 & 0.136 & 1.45 & 0.79 & -0.10 to 2.99 & 0.066 \\
\hline & Met/Met & 1.22 & 0.72 & -0.19 to 2.63 & 0.089 & 1.18 & 0.81 & -0.40 to 2.77 & 0.144 \\
\hline
\end{tabular}




\begin{tabular}{|c|c|c|c|c|c|c|c|c|c|}
\hline \multirow[t]{2}{*}{ COMT rs4680 } & Met/Val & -1.03 & 1.17 & -3.33 to 1.26 & 0.379 & -0.71 & 1.19 & -3.04 to 1.62 & 0.550 \\
\hline & Met/Met & -0.68 & 1.31 & -3.25 to 1.89 & 0.605 & -0.71 & 1.36 & -3.38 to 1.97 & 0.605 \\
\hline \multicolumn{10}{|l|}{ HA } \\
\hline \multirow[t]{2}{*}{ COMT rs4680 } & Met/Val & 0.43 & 1.27 & -2.05 to 2.91 & 0.735 & 0.70 & 1.27 & -1.79 to 3.19 & 0.581 \\
\hline & Met/Met & -0.18 & 1.40 & -2.92 to 2.57 & 0.901 & -0.07 & 1.44 & -2.89 to 2.75 & 0.961 \\
\hline \multicolumn{10}{|l|}{ RD } \\
\hline \multirow[t]{2}{*}{ COMT rs4680 } & Met/Val & 0.27 & 0.90 & -1.49 to 2.04 & 0.760 & 0.39 & 0.89 & -1.34 to 2.13 & 0.656 \\
\hline & Met/Met & -0.69 & 1.00 & -2.65 to 1.26 & 0.486 & -0.12 & 1.01 & -2.09 to 1.86 & 0.909 \\
\hline \multicolumn{10}{|c|}{ Concussion history } \\
\hline NS & & -0.01 & 0.04 & -0.08 to 0.06 & 0.719 & 0.00 & 0.04 & -0.08 to 0.07 & 0.910 \\
\hline HA & & 0.10 & 0.04 & 0.03 to 0.18 & 0.005 & 0.11 & 0.04 & 0.03 to 0.18 & 0.006 \\
\hline $\mathrm{RD}$ & & 0.01 & 0.05 & -0.09 to 0.10 & 0.867 & 0.03 & 0.05 & -0.07 to 0.13 & 0.591 \\
\hline \multirow[t]{2}{*}{ COMT rs4680 } & Met/Val & 0.22 & 0.49 & -0.73 to 1.17 & 0.649 & 0.16 & 0.49 & -0.80 to 1.13 & 0.740 \\
\hline & Met/Met & 0.09 & 0.54 & -0.97 to 1.14 & 0.872 & -0.21 & 0.56 & -1.31 to 0.88 & 0.704 \\
\hline
\end{tabular}

The COMT rs4680 Val/Val genotype was used as the reference genotype for the analysis. Statistically significant differences $(P<0.05)$ are displayed in bold. SE: Standard error of the mean; 95\% CI: 95\% confidence interval. 


\section{Table SII:}

The summarized results of the generalized structural equation model analysis that assessed the collective relationship between concussion history, novelty seeking (NS), harm avoidance (HA), and reward dependence (RD) personality scores, and 5-HTTLPR, in conjunction with SLC6A4 rs25531, genotype ("low": $\mathrm{S}_{\mathrm{A}} / \mathrm{S}_{\mathrm{A}}$; "intermediate": $\mathrm{S}_{\mathrm{A}} / \mathrm{L}_{\mathrm{A}}, \mathrm{S}_{\mathrm{A}} / \mathrm{L}_{\mathrm{G}}, \mathrm{L}_{\mathrm{A}} / \mathrm{L}_{\mathrm{G}}, \mathrm{L}_{\mathrm{G}} / \mathrm{L}_{\mathrm{G}}$; "high": $\mathrm{L}_{\mathrm{A}} / \mathrm{L}_{\mathrm{A}}$ ) in in junior (high school) and senior (senior community-level amateur and senior professional) rugby participants without a previous suspected or diagnosed concussion (control) compared to those with a minimum of one suspected or diagnosed concussion (case all) or case participants with one or more diagnosed concussions (case diagnosed only). Separate models were constructed for the control versus case (all) group and the control group compared to the case (diagnosed only) subgroup, in each level of play (all levels, junior, and senior).

\begin{tabular}{|c|c|c|c|c|c|c|c|c|c|}
\hline & & \multicolumn{4}{|c|}{ Control vs. case (all) } & \multicolumn{4}{|c|}{ Control vs. case (diagnosed only) } \\
\hline & & Coefficient & SE & $95 \% \mathrm{CI}$ & $P$ value & Coefficient & SE & $95 \% \mathrm{CI}$ & $P$ value \\
\hline \multicolumn{10}{|l|}{ All levels } \\
\hline \multicolumn{10}{|l|}{ NS } \\
\hline \multirow{2}{*}{ 5-HTTLPR } & Intermediate & -0.81 & 0.95 & -2.68 to 1.05 & 0.392 & -0.72 & 0.97 & -2.61 to 1.17 & 0.456 \\
\hline & High & -1.07 & 1.14 & -3.30 to 1.17 & 0.350 & -0.97 & 1.16 & -3.25 to 1.31 & 0.403 \\
\hline \multicolumn{10}{|l|}{ HA } \\
\hline \multirow{2}{*}{ 5-HTTLPR } & Intermediate & 0.62 & 1.06 & -1.46 to 2.71 & 0.557 & 0.56 & 1.08 & -1.55 to 2.67 & 0.601 \\
\hline & High & 0.46 & 1.28 & -2.05 to 2.97 & 0.717 & 1.20 & 1.29 & -1.34 to 3.74 & 0.355 \\
\hline \multicolumn{10}{|l|}{ RD } \\
\hline \multirow{2}{*}{ 5-HTTLPR } & Intermediate & 0.17 & 0.76 & -1.33 to 1.66 & 0.827 & 0.24 & 0.77 & -1.27 to 1.75 & 0.753 \\
\hline & High & 1.06 & 0.94 & -0.79 to 2.91 & 0.260 & 1.11 & 0.95 & -0.75 to 2.98 & 0.241 \\
\hline
\end{tabular}




\begin{tabular}{|c|c|c|c|c|c|c|c|c|c|}
\hline \multicolumn{10}{|c|}{ Concussion history } \\
\hline NS & & -0.01 & 0.03 & -0.07 to 0.05 & 0.769 & 0.00 & 0.03 & -0.07 to 0.06 & 0.895 \\
\hline HA & & 0.03 & 0.03 & -0.03 to 0.08 & 0.319 & 0.02 & 0.03 & -0.03 to 0.08 & 0.394 \\
\hline $\mathrm{RD}$ & & 0.01 & 0.04 & -0.06 to 0.09 & 0.714 & 0.03 & 0.04 & -0.04 to 0.11 & 0.383 \\
\hline \multirow[t]{2}{*}{ 5-HTTLPR } & Intermediate & -0.79 & 0.41 & -1.59 to 0.02 & 0.056 & -1.06 & 0.42 & -1.88 to -0.24 & 0.011 \\
\hline & High & -0.87 & 0.49 & -1.84 to 0.09 & 0.075 & -1.01 & 0.50 & -1.99 to -0.04 & 0.042 \\
\hline \multicolumn{10}{|l|}{ Junior } \\
\hline \multicolumn{10}{|l|}{ NS } \\
\hline \multirow{2}{*}{ 5-HTTLPR } & Intermediate & -0.03 & 1.31 & -2.60 to 2.55 & 0.985 & 0.01 & 1.35 & -2.64 to 2.65 & 0.997 \\
\hline & High & -2.56 & 1.72 & -5.94 to 0.82 & 0.138 & -2.56 & 1.74 & -5.97 to 0.85 & 0.141 \\
\hline \multicolumn{10}{|l|}{ HA } \\
\hline \multirow{2}{*}{ 5-HTTLPR } & Intermediate & -0.32 & 1.59 & -3.43 to 2.79 & 0.840 & 0.26 & 1.65 & -2.98 to 3.50 & 0.874 \\
\hline & High & 4.20 & 2.08 & 0.13 to 8.27 & 0.043 & 4.62 & 2.10 & 0.51 to 8.73 & 0.028 \\
\hline \multicolumn{10}{|l|}{ RD } \\
\hline \multirow{2}{*}{ 5-HTTLPR } & Intermediate & 0.16 & 1.24 & -2.28 to 2.60 & 0.896 & 0.18 & 1.29 & -2.36 to 2.72 & 0.890 \\
\hline & High & 1.47 & 1.67 & -1.81 to 4.75 & 0.379 & 1.24 & 1.69 & -2.07 to 4.56 & 0.462 \\
\hline \multicolumn{10}{|c|}{ Concussion history } \\
\hline NS & & -0.02 & 0.06 & -0.13 to 0.10 & 0.790 & -0.01 & 0.07 & -0.14 to 0.12 & 0.865 \\
\hline HA & & -0.10 & 0.05 & -0.20 to 0.01 & 0.074 & -0.12 & 0.06 & -0.24 to 0.00 & 0.049 \\
\hline $\mathrm{RD}$ & & 0.01 & 0.06 & -0.11 to 0.13 & 0.901 & 0.05 & 0.07 & -0.09 to 0.18 & 0.502 \\
\hline \multirow[t]{2}{*}{ 5-HTTLPR } & Intermediate & -0.83 & 0.67 & -2.14 to 0.47 & 0.210 & -1.31 & 0.70 & -2.68 to 0.06 & 0.061 \\
\hline & High & -1.64 & 1.02 & -3.63 to 0.35 & 0.107 & -1.65 & 1.04 & -3.69 to 0.381 & 0.111 \\
\hline
\end{tabular}




\begin{tabular}{|c|c|c|c|c|c|c|c|c|c|}
\hline \multicolumn{10}{|l|}{ NS } \\
\hline \multirow[t]{2}{*}{ 5-HTTLPR } & Intermediate & -1.26 & 1.28 & -3.76 to 1.24 & 0.322 & -1.13 & 1.29 & -3.65 to 1.39 & 0.380 \\
\hline & High & -0.69 & 1.48 & -3.58 to 2.21 & 0.641 & -0.47 & 1.50 & -3.42 to 2.48 & 0.754 \\
\hline \multicolumn{10}{|l|}{ HA } \\
\hline \multirow{2}{*}{ 5-HTTLPR } & Intermediate & 1.24 & 1.35 & -1.41 to 3.89 & 0.360 & 0.76 & 1.35 & -1.89 to 3.41 & 0.575 \\
\hline & High & -0.74 & 1.57 & -3.82 to 2.34 & 0.639 & -0.14 & 1.59 & -3.25 to 2.96 & 0.927 \\
\hline \multicolumn{10}{|l|}{ RD } \\
\hline \multirow{2}{*}{ 5-HTTLPR } & Intermediate & 0.05 & 0.94 & -1.79 to 1.89 & 0.957 & 0.19 & 0.94 & -1.65 to 2.02 & 0.840 \\
\hline & High & 0.61 & 1.12 & -1.59 to 2.82 & 0.586 & 0.87 & 1.13 & -1.34 to 3.07 & 0.440 \\
\hline \multicolumn{10}{|c|}{ Concussion history } \\
\hline NS & & -0.01 & 0.04 & -0.08 to 0.06 & 0.817 & 0.00 & 0.04 & -0.08 to 0.07 & 0.932 \\
\hline HA & & 0.12 & 0.04 & 0.04 to 0.20 & 0.002 & 0.12 & 0.04 & 0.04 to 0.20 & 0.004 \\
\hline $\mathrm{RD}$ & & 0.02 & 0.05 & -0.08 to 0.12 & 0.713 & 0.03 & 0.05 & -0.08 to 0.14 & 0.599 \\
\hline \multirow[t]{2}{*}{ 5-HTTLPR } & Intermediate & -1.03 & 0.57 & -2.14 to 0.09 & 0.072 & -1.19 & 0.57 & -2.31 to -0.07 & $\mathbf{0 . 0 3 7}$ \\
\hline & High & -0.48 & 0.65 & -1.75 to 0.80 & 0.463 & -0.66 & 0.65 & -1.94 to 0.62 & 0.311 \\
\hline
\end{tabular}

The 5-HTTLPR low genotype group was used as the reference genotype for the analysis. Statistically significant differences $(P<0.05)$ are displayed in bold. SE: Standard error of the mean; 95\% CI: 95\% confidence interval. 